\title{
Clinical Trials For Cytoprotection In Stroke
}

\author{
Lise A. Labiche and James C. Grotta \\ Stroke Program, University of Texas at Houston Medical School, 6431 Fannin Street, Houston, Texas 77030
}

Summary: To date, many cytoprotective drugs have reached the stage of pivotal phase 3 efficacy trials in acute stroke patients. (Table 1) Unfortunately, throughout the neuroprotective literature, the phrase "failure to demonstrate efficacy" prevails as a common thread among the many neutral or negative trials, despite the largely encouraging results encountered in preclinical studies. The reasons for this discrepancy are multiple, and have been discussed by Dr. Zivin in his review. Many of the recent trials have addressed deficiencies of the previous ones with more rigorous trial design, including more specific patient selection criteria (ensure homogeneity of stroke location and severity), stratified randomization algorithms (time-totreat), narrowed therapeutic time-window and pharmacokinetic monitoring. Current trials have also incorporated biologic surrogate markers of toxicity and outcome such as drug levels and neuroimaging. Lastly, multi-modal therapies and coupled cytoprotection/reperfusion strategies are being investigated to optimize tissue salvage. This review will focus on individual therapeutic strategies and we will emphasize what we have learned from these trials both in terms of trial design and the biologic effect (or lack thereof) of these agents. Key Words: Stroke, neuroprotection, ischemia, treatment, clinical trials.

\section{Calcium antagonists}

The first practical pharmacologic agents to be clinically evaluated for cytoprotection in stroke were the calcium channel antagonists. There are several classes of calcium channels that play a role in brain ischemia. The presynaptic voltage-activated N-type calcium channels are largely restricted to neurons and regulate neurotransmitter release. The ubiquitous voltage-gated L-type calcium channels trigger excitation-contraction coupling in smooth muscle and regulate vasomotor tone. These L-type calcium channels are sensitive to the dihydropyridine compounds, of which nimodipine and nicardipine are examples. Calcium influx through NMDA receptor-mediated channels is both ligand- and voltage-dependent. ${ }^{1}$

The calcium channel antagonist that has undergone the most extensive investigation in stroke is nimodipine. ${ }^{2}$ Several randomized controlled clinical studies have conclusively demonstrated the effectiveness of nimodipine in preventing ischemic neurologic deficit and poor outcome secondary to aneurysmal subarachnoid hemorrhage. ${ }^{3-7}$ Prophylactic therapy with nimodipine is now standard treatment in subarachnoid hemorrhage. The usual dose is $60 \mathrm{mg}$ orally every $4 \mathrm{~h}$ for 21 days, but a lower dose or a more frequent dosing schedule may be

Address correspondence and reprint requests to James C. Grotta, Stroke Program, University of Texas at Houston Medical School, 6431 Fannin Street, Houston, TX 77030. E-mail: james.c.grotta@uth.tmc.edu. used if hypotension is limiting. Although it is uncertain whether nimodipine has its primary effect in this clinical setting as a cytoprotective drug or as a vasodilator, the use of nimodipine does not result in angiographically evident improvement of vasospasm.

Oral nimodipine has been investigated in ischemic stroke in at least 29 randomized placebo-controlled trials. These studies enrolled patients with time windows ranging from 6 to $48 \mathrm{~h}$, used nimodipine doses between 60 and $240 \mathrm{mg} / \mathrm{day}$, and treated for periods of 14 to 28 days. A few of the earlier studies found a significant difference in mortality and neurologic function in favor of nimodipine therapy ${ }^{8-11}$; however, subsequent larger studies and a recent meta-analysis failed to replicate this benefit. ${ }^{12}$ Several studies have actually shown a better outcome in the placebo-treated patients, a finding attributed to hypotension induced by both oral and intravenous administration of the drug. ${ }^{13-15}$

The most recent and extensive meta-analysis of 22 calcium antagonist trials, studying over 6,800 patients, failed to demonstrate any beneficial effect of treatment, even in early treatment subgroups (within $12 \mathrm{~h}$ of stroke onset) (FIG. 1). ${ }^{16}$ In addition, meta-analysis limited to the "good" quality trials found a statistically significant negative effect of calcium antagonists. In fact, the results from this meta-analysis prompted the premature termination of the Very Early Nimodipine Use in Stroke (VE- 
TABLE 1. Past and Current Cytoprotective Clinical Trials

\begin{tabular}{|c|c|c|c|c|c|c|c|c|c|}
\hline Drug & Phase & $\begin{array}{c}\text { Latest Extent } \\
\text { of Time } \\
\text { Window }\end{array}$ & $\begin{array}{l}\text { Adeq. } \\
\text { Power } \infty\end{array}$ & $\begin{array}{l}\text { Adeq. } \\
\text { Dose }\end{array}$ & Dose-Limiting AEs & $\begin{array}{l}\text { Homogen } \\
\text { Patient } \\
\text { Population }\end{array}$ & $\begin{array}{l}\text { Linked } \\
\text { to TPA }\end{array}$ & $\begin{array}{c}\text { Biologic } \\
\text { Imaging } \\
\text { Marker }\end{array}$ & Results \\
\hline \multicolumn{10}{|l|}{ Calcium Antagonists } \\
\hline $\begin{array}{l}\text { Nimodipine } \\
\text { Nicardipine }\end{array}$ & $\begin{array}{l}3 \\
2\end{array}$ & $\begin{array}{l}6-48 \mathrm{~h} \\
12 \mathrm{~h}\end{array}$ & + & & $\begin{array}{l}\text { Hypotension } \\
\text { Hypotension }\end{array}$ & & & & $\begin{array}{l}\text { Neutral } \\
\text { Neutral }\end{array}$ \\
\hline \multicolumn{10}{|l|}{ Glutamate Antagonists } \\
\hline Selfotel & 3 & $6-12 \mathrm{~h}$ & + & No & Neuropsych & & & & Negative \\
\hline Dextrorphan & 2 & $48 \mathrm{~h}$ & & Yes & Neuropsych & & & & Neutral \\
\hline Cerestat & 3 & $6-24 \mathrm{~h}$ & + & Yes & Hypertension & & & & Negative \\
\hline AR-R15696 & 2 & $12 \mathrm{~h}$ & & Yes & Neuropsych & & & & Neutral \\
\hline Magnesium & $3^{*}$ & $2-12 \mathrm{~h}$ & + & Yes & No & + & & + & $?$ \\
\hline \multicolumn{10}{|l|}{ AMPA Antagonists } \\
\hline YM872 & $2 \mathrm{~b}$ & $3-6 \mathrm{~h}$ & + & ? & $?$ & + & + & + & Neutral \\
\hline ZK200775 & 2 & $24 \mathrm{~h}$ & & $?$ & Sedation & & & + & Negative \\
\hline \multicolumn{10}{|l|}{ Indirect Glutamate Modulators } \\
\hline Eliprodil & 3 & $?$ & $?$ & $?$ & ? & $?$ & ? & $?$ & Negative \\
\hline Gavestinel & 3 & $6 \mathrm{~h}$ & $+^{\dagger}$ & Yes & No & + & & & Neutral \\
\hline Sipatrigine & 2 & $12 \mathrm{~h}$ & & $?$ & Neuropsych & + & & & Negative \\
\hline Fosphenytoin & $2 / 3$ & $4 \mathrm{~h}$ & + & ? & No & & & & Neutral \\
\hline BMS-204352 & 3 & $6 \mathrm{~h}$ & + & $?$ & No & + & & + & Neutral \\
\hline Lifarizine & 2 & $?$ & & $?$ & Hypotension & & & & Neutral \\
\hline Lubeluzole & 3 & $4-8 \mathrm{~h}$ & $+^{\dagger}$ & No & Cardiac & + & + & & Neutral \\
\hline \multicolumn{10}{|l|}{ Other Neurotrans Modulators } \\
\hline Trazadone & 2 & $?$ & $?$ & $?$ & $?$ & $?$ & ? & $?$ & Neutral \\
\hline Repinotan & $3^{*}$ & $6 \mathrm{~h}$ & $+^{\dagger}$ & Yes & ? & + & & & $?$ \\
\hline ONO-2506 & $2 / 3^{*}$ & $6 \mathrm{~h}$ & + & $?$ & $?$ & + & & & $?$ \\
\hline \multicolumn{10}{|l|}{ Opioid antagonist } \\
\hline Naloxone & 2 & $8-60 \mathrm{~h}$ & & $?$ & No & & & & Neutral \\
\hline Nalmefene & 3 & $6 \mathrm{~h}$ & $+^{\dagger}$ & $?$ & No & + & & & Neutral \\
\hline \multicolumn{10}{|l|}{ GABA agonist } \\
\hline Clomethiazole & 3 & $12 \mathrm{~h}$ & $+^{\dagger}$ & Yes & Sedation & + & & & Neutral \\
\hline Diazepam & $3^{*}$ & $12 \mathrm{~h}$ & + & $?$ & $?$ & & & & $?$ \\
\hline \multicolumn{10}{|l|}{ Free Radical Scavengers } \\
\hline Tirilazad & 3 & $6 \mathrm{~h}$ & + & $?$ & No & & & + & Negative \\
\hline Ebselen & $3^{*}$ & $48 \mathrm{~h}$ & + & $?$ & $?$ & + & & & $?$ \\
\hline NXY-059 & $2 \mathrm{~b} / 3^{*}$ & $6 \mathrm{~h}$ & $+^{\dagger}$ & $?$ & $?$ & + & & & $?$ \\
\hline \multicolumn{10}{|l|}{ Anti-inflammatory Agents } \\
\hline Enlimomab & 3 & $6 \mathrm{~h}$ & + & Yes & Fever & + & & & Negative \\
\hline LeukArrest & 3 & $12 \mathrm{~h}$ & $?$ & ? & $?$ & & & & Neutral \\
\hline FK-506 & $2^{*}$ & $12 \mathrm{~h}$ & & $?$ & $?$ & + & & & \\
\hline Steroids & 2 & $48 \mathrm{~h}$ & & $?$ & Infection & & & & Negative \\
\hline \multicolumn{10}{|l|}{$\begin{array}{l}\text { Membrane Stabilizers/Trophic } \\
\text { Factor }\end{array}$} \\
\hline GM1 & 3 & $72 \mathrm{~h}$ & + & $?$ & No & & & & Neutral \\
\hline Cerebrolysin & 2 & $12-24 \mathrm{~h}$ & & $?$ & No & & & & $\begin{array}{l}\text { Positive } \\
\text { Trend }\end{array}$ \\
\hline Citicoline & 3 & $24 \mathrm{~h}$ & $+^{\dagger}$ & $?$ & No & + & & + & $\begin{array}{l}\text { Positive } \\
\text { Post hoc }\end{array}$ \\
\hline EPO & $2 \mathrm{a}^{*}$ & & & & & & & & \\
\hline bFGF & $2 / 3$ & $6 \mathrm{~h}$ & + & $?$ & Hypotension & + & & & Negative \\
\hline Hypothermia & $2^{*}$ & $5-24 \mathrm{~h}$ & & Yes & $\begin{array}{l}\text { Pneumonia, } \\
\text { arrhythmias, hy- } \\
\text { potension }\end{array}$ & + & & + & $?$ \\
\hline Caffeinol Oxygen Delivery & $2^{*}$ & $4-6 \mathrm{~h}$ & & Yes & No & + & & & $?$ \\
\hline $\mathrm{DCLHb}$ & 2 & $18 \mathrm{~h}$ & & $?$ & HTN & & & & Negative \\
\hline HBO & $2 / 3^{*}$ & $24 \mathrm{~h}$ & & $?$ & $?$ & & & & Neutral \\
\hline
\end{tabular}

Only relevant to phase $2 b$ or 3 efficacy trials.

* Currently enrolling.

${ }^{\dagger}$ Not adequately powered for TPA subgroup.

$+=$ positive; $\mathrm{HTN}=$ hypertension; $\mathrm{AE}=$ adverse effects; Neuropsych $=$ Neuropsychiatric side effects. 
Poor outcome; Rx 1765/3825, P 1256/3052

Mortality at end of follow-up; Rx 911/4145, P 699/3377

Mortality at end of treatment; Rx 496/3533, P 374/2915

Adverse events; Rx 256/2954, P 163/2435

Route of administration*:

Oral; Rx 1272/2954, P 916/2370

Intravenous; Rx 493/862, P 340/682

Start of treatment*:

Early; Rx 523/1147, P 364/925

Late; Rx 1099/2310, P 777/1762

Quality of trial*:

Good; Rx 1230/2492, P 773/1855

Moderate; Rx 360/1045, P 366/983

Poor; Rx 175/288, P 117/214

Publication status*:

Published; Rx 1511/3381, P 1084/2699

Unpublished; Rx 254/435, P 172/353

0

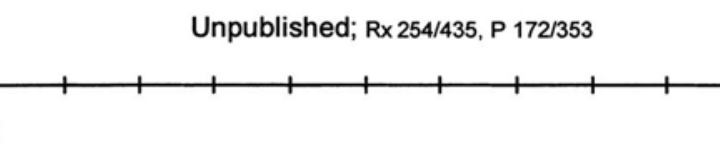

RR $1.04,95 \%$ Cl 0.98 to 1.09

RR $1.07,95 \% \mathrm{Cl} 0.98$ to 1.17

RR $1.06,95 \% \mathrm{Cl} 0.93$ to 1.20

RR $1.17,95 \% \mathrm{Cl} 0.97$ to 1.41

RR $1.02,95 \% \mathrm{Cl} 0.95$ to 1.09

RR $1.09,95 \% \mathrm{Cl} 0.99$ to 1.20

RR $1.07,95 \% \mathrm{Cl} 0.97$ to 1.18

RR $1.00,95 \% \mathrm{Cl} 0.97$ to 1.08

RR $1.09,95 \% \mathrm{Cl} 1.02$ to 1.16

RR $0.92,95 \% \mathrm{Cl} 0.82$ to 1.03

RR $1.04,95 \% \mathrm{Cl} 0.89$ to 1.21

RR $1.02,95 \% \mathrm{Cl} 0.96$ to 1.08

RR $1.14,95 \% \mathrm{Cl} 1.00$ to 1.30

FIG. 1. Meta-analysis of 22 calcium antagonist acute stroke trials. $R x=$ treatment group; $P=$ placebo group. From Horn and Limburg. Calcium antagonists for ischemic stroke: a systematic review. Stroke 32:570-576. Copyright (C) 2001, Lippincott Williams and Wilkins. All rights reserved.

NUS) trial that was designed to determine the efficacy of nimodipine administered within $6 \mathrm{~h}$ of stroke onset. ${ }^{17}$ The interim analysis of 454 patients showed no effect of nimodipine; however, within the ischemic stroke subgroup an increase in poor outcome at 3 months was found in the nimodipine-treated patients [relative risk 1.4, 95\% confidence interval (CI) 1.0-2.1] (Table 2).

Another dihydropyridine calcium channel antagonist, nicardipine, has also been tested in a pilot stroke study. ${ }^{18}$ Hypotension was a frequent, dose-related side effect.

The lack of effect, or presence of detrimental effect, of calcium antagonists may be due to the hypotension caused by blocking the vascular smooth muscle cells. Another plausible explanation for the failure of calcium antagonists is that neurotransmitter release is a proximal event in the excitotoxic cascade with immediate effects; therefore, any delay in drug administration prevents its theoretical efficacy in preventing cell necrosis. Delayed or prolonged use of L-type antagonists may actually induce apoptotic cell death since modest increases in calcium inhibit apoptosis. ${ }^{19}$ This mechanism may overcome other protective actions of these agents.

TABLE 2. Results from VENUS Study Subgroup Analyses of Patients with Poor Outcome in Each Group

\begin{tabular}{|c|c|c|c|c|}
\hline & Nimodipine & Placebo & $\mathrm{RR}$ & $95 \% \mathrm{CI}$ \\
\hline Ischemic stroke & $n=133$ & $n=128$ & & \\
\hline Poor outcome at 3 months & $44(34)$ & $30(24)$ & 1.4 & $1.0-2.1$ \\
\hline Hemorrhagic stroke & $n=20$ & $n=15$ & & \\
\hline Poor outcome at 3 months & $11(58)$ & $9(60)$ & 1.0 & $0.6-1.7$ \\
\hline No CT scan & $n=71$ & $n=79$ & & \\
\hline Poor outcome at 3 months & $16(23)$ & $21(27)$ & 0.8 & $0.5-1.5$ \\
\hline Per protocol* ${ }^{*}$ & $n=179$ & $n=168$ & & \\
\hline Poor outcome at 3 months & $56(31)$ & $47(28)$ & 1.1 & $0.8-1.6$ \\
\hline
\end{tabular}

* 107 patients were excluded from this analysis because of the following exclusion criteria: 8 , other diagnosis; 74 , hemiparesis not severe enough; 8 , age $>85$ years; 10 , swallowing disturbance; and 7 , other exclusion criteria. ${ }^{17}$

Values are number $(\%)$ unless indicated otherwise.

$\mathrm{CI}=$ confidence interval; $\mathrm{RR}=$ relative risk.

From Horn et al. Very early nimodipine use in stroke (VENUS): a randomized, double-blind, placebo-controlled trial. Stroke 32:461.

Copyright (C) 2001, Lippincott Williams and Wilkins. All rights reserved. 


\section{Glutamate antagonists}

$N$-methyl-D-aspartate (NMDA) receptor antagonists were the first class of acute stroke therapeutic agents to proceed from development in the laboratory to testing in humans, employing modern principles of clinical trial design, most important relatively early treatment. The potential utility of NMDA antagonists in stroke was first recognized when it was observed that a hypoxic or ischemic insult results in elevation of brain levels of the excitatory neurotransmitter glutamate. The excitotoxic theory of ischemic brain injury implicates glutamate as a pivotal mediator of cell death via ligand-gated receptors (NMDA and AMPA receptors). The NMDA receptor is a complex ligand-gated ion channel that requires activation by glutamate and glycine, as well as concomitant membrane depolarization to overcome a voltage-dependent block by magnesium ions.

The complex structure of the NMDA receptor provides multiple sites for therapeutic inhibition. Competitive NMDA antagonists bind directly to the glutamate site of the NMDA receptor to inhibit the action of glutamate. Noncompetitive antagonists block the NMDA-associated ion channel in a use-dependent manner. Other sites on the NMDA receptor susceptible to antagonism include the glycine site and the polyamine site. Prototypes of these competitive and noncompetitive NMDA antagonists have been studied in phase 3 clinical trials for the treatment of stroke.

Selfotel (CGS19755) is a competitive NMDA receptor antagonist that limits neuronal damage in animal stroke models. $^{20-22}$ Selfotel was evaluated in a randomized, double-blind, placebo-controlled, ascending dose phase 2a study to determine its safety and tolerability, and obtain pharmacokinetic and preliminary efficacy data. ${ }^{23}$ Patients were treated within $12 \mathrm{~h}$ of ischemic hemispheric stroke onset. Non-CNS adverse effects were infrequent and not different between the Selfotel and placebo groups. Neuro-psychiatric adverse experiences were common, dose-related, and lasted an average of $24 \mathrm{~h}$. Symptoms included hallucinations, agitation, confusion, dysarthria, ataxia, delirium, paranoia, and somnolence. Patients experienced mild adverse experiences with Selfotel $1.5 \mathrm{mg} / \mathrm{kg}$; however, when the dose was increased to $2 \mathrm{mg} / \mathrm{kg}$ given once or twice, adverse experiences occurred in all patients. Based on these data, phase 3 parallel studies of a single dose of $1.5 \mathrm{mg} / \mathrm{kg}$ of Selfotel given within $6 \mathrm{~h}$ of the onset of acute hemispheric stroke were begun in the United States and Europe, but were suspended after $31 \%$ of planned enrollment because of an unfavorable efficacy/toxicity ratio. ${ }^{24}$ Intention-to-treat analyses demonstrated that adverse events were more common and more often neurologic in the Selfotel group (Table 3). In addition, the proportion of patients with neurologic progression or decreased arousal was higher in the Selfotel group, as were both 8-
TABLE 3. Summary of the Most Frequency Occurring Adverse Experiences by Treatment Group

\begin{tabular}{lccc}
\hline & \multicolumn{3}{c}{ Treatment Group } \\
\cline { 2 - 4 } Adverse Experience & Selfotel & Placebo & $p^{*}$ \\
\hline Agitation & $101(36)$ & $39(1)$ & 0.001 \\
Hallucination & $59(21)$ & $13(5)$ & 0.001 \\
Fever & $52(19)$ & $53(19)$ & \\
Hypertension & $47(17)$ & $28(10)$ & 0.015 \\
Confusion & $46(16)$ & $16(6)$ & 0.001 \\
Constipation & $37(13)$ & $55(19)$ & 0.052 \\
Headache & $35(13)$ & $55(19)$ & \\
Somnolence & $30(11)$ & $29(10)$ & \\
Cerebrovascular disorder & $29(10)$ & $13(5)$ & 0.009 \\
Urinary tract infection & $29(10)$ & $36(13)$ & \\
Vomiting & $19(7)$ & $30(11)$ & \\
Coma & $15(5.3)$ & $7(2.4)$ & 0.075 \\
Stupor & $12(4.3)$ & 0 & 0.001 \\
\hline
\end{tabular}

* Adverse experiences were reported by $>10 \%$ of patients treated with Selfotel or placebo; by univariate analysis. ${ }^{24}$

Values are number of patients (\%) with adverse experiences.

From Davis et al. Selfotel in acute ischemic stroke: possible neurotoxic effects of an NMDA antagonist. Stroke 31:347-354. Copyright (C) 2000, Lippincott Williams and Wilkins. All rights reserved.

and 30-day mortality. There was no difference between Selfotel and placebo in the primary endpoint of functional independence (Table 4). Although there was no statistical difference in mortality over the entire study, post hoc analysis revealed a statistically significant increase in 8- and 30-day mortality in the Selfotel group (Table 5).

It may be concluded from these trials that Selfotel is not efficacious as a cytoprotectant and may potentially exert a neurotoxic effect in patients with severe stroke. The Selfotel trials exhibit an important principle of cytoprotectant failure: the narrow therapeutic index. Animal models determined that a plasma level of $40 \mu \mathrm{g} / \mathrm{ml}$ Selfotel was cytoprotective. However, the highest tolerated level in human stroke patients was only half of this target cytoprotective concentration $(21 \mu \mathrm{g} / \mathrm{ml})$ and even

TABLE 4. Primary Outcome: Proportion of Patients with Total Barthel Index Score of $>60$

\begin{tabular}{lccc}
\hline Stroke Severity & Selfotel $\%$ & Placebo $\%$ & $p^{*}$ \\
\hline 3 months & & & \\
Mild/moderate & 83 & 83 & 0.981 \\
Severe & 48 & 43 & 0.352 \\
All patients & 61 & 58 & 0.490 \\
3 months LOCF & & & \\
Mild/moderate & 79 & 78 & 0.852 \\
Severe & 35 & 35 & 0.981 \\
All patients & 50 & 50 & 0.853 \\
\hline
\end{tabular}

LOCF $=$ last observation carried forward. ${ }^{24}$

From Davis et al. Selfotel in acute ischemic stroke: possible neurotoxic effects of an NMDA antagonist. Stroke 31:347-354. Copyright (C) 2000, Lippincott Williams and Wilkins. All rights reserved. 
TABLE 5. Relative Risk of Mortality for Stroke Patients Receiving Selfotel versus Placebo, by Stroke Severity

\begin{tabular}{lcccc}
\hline Indication & Selfotel, \% $(\mathrm{n} / \mathrm{N})$ & Placebo, \% $(\mathrm{n} / \mathrm{N})$ & Relative Risk & CI \\
\hline All deaths & & & & \\
$\quad$ All patients & $22.1(62 / 280)^{*}$ & $17.1(49 / 286)$ & 1.292 & $(0.923,1.809)$ \\
$\quad$ Severe patients & $30.5(57 / 187)$ & $21.6(40 / 185)$ & 1.410 & $(0.994,1.999)$ \\
$\quad$ Mild/moderate patients & $4.3(4 / 92)$ & $8.9(9 / 101)$ & 0.488 & $(0.156,1.531)$ \\
Deaths by day 8 & $11.4(32 / 280)^{*}$ & $5.9(17 / 286)$ & & 1.923 \\
$\quad$ All patients & $16.6(31 / 187)$ & $9.2(17 / 185)$ & 1.804 & $(1.093,3.382)$ \\
$\quad$ Severe patients & $0.6(0 / 92)$ & $0.0(0 / 101)$ & & \\
Mild/moderate patients & & & \\
\hline
\end{tabular}

* Includes one Selfotel patient (patient 402 in protocol 10) who had no baseline stroke severity score and died on day $2 .{ }^{24}$ $\mathrm{CI}=$ confidence interval; $\mathrm{n}=$ number of patients dying; $\mathrm{N}=$ total number of patients.

From Davis et al. Selfotel in acute ischemic stroke: possible neurotoxic effects of an NMDA antagonist. Stroke 31:347-354. Copyright @ 2000, Lippincott Williams and Wilkins. All rights reserved.

these "subtherapeutic" levels produced marked neurological and psychiatric effects. ${ }^{25}$

The noncompetitive NMDA antagonist dextrorphan was also evaluated in a pilot study. ${ }^{26}$ Patients were enrolled in this study within $48 \mathrm{~h}$ of the onset of hemispheric cerebral infarction. As with Selfotel, adverse effects of dextrorphan occurred in a dose-dependent manner, including agitation, confusion, hallucinations, nystagmus, somnolence, nausea, and vomiting. Hypotension occurred at the highest loading doses $(>200 \mathrm{mg} / \mathrm{h})$, but was not associated with neurologic deterioration. There were no apparent differences in the outcome between placebo patients or low-, medium-, or high-dose dextrorphan patients. Unlike Selfotel, plasma concentrations of dextrorphan were achieved that were comparable to the cytoprotective level determined in cell culture and animal models. At the present time, no further clinical trials of dextrorphan are in progress.

A phase 2a dose escalation and tolerability study of the noncompetitive NMDA antagonist CNS1102 (Cerestat, aptiganel) was reported in patients within $18 \mathrm{~h}$ of stroke onset. ${ }^{27}$ Side effects observed were hypertension, headache, sedation, nausea, vomiting, disorientation, and paresthesias. Of 94 patients, 10 had mild to moderate agitation or confusion, which seemed to be less severe than the side effects seen with Selfotel and dextrorphan.

A multicenter placebo-controlled, double-blind randomized trial was then conducted to evaluate the safety and tolerability of escalating doses of Cerestat, and to determine the pharmacokinetic properties of the drug. ${ }^{28}$ Forty-six patients with ischemic carotid artery territory stroke [National Institute of Health Stroke Scale (NIHSS) score 4-20] were enrolled within $24 \mathrm{~h}$ of symptom onset. In part A, patients were randomized 3:1 to a single bolus of Cerestat or placebo. Doses up to $6 \mathrm{mg}$ were well tolerated; however, $7.5 \mathrm{mg}$ caused more frequent and more severe side effects (sedation, hallucination, confusion). In phase $\mathrm{B}$, a constant, optimal bolus dose (6 $\mathrm{mg}$ as determined in part A) was followed by a 6- to 12 -h continuous infusion of $1 \mathrm{mg} / \mathrm{hr}$. However, the dosing regimen in part $\mathrm{B}$ was abandoned due to hypertension and severe sedation. Therefore, a lower dose regimen was adopted $(4.5 \mathrm{mg}$ bolus, followed by 0.75 $\mathrm{mg} / \mathrm{hr}$ infusion). The lower dose regimen successfully achieved the target cytoprotective plasma concentration $>10 \mathrm{ng} / \mathrm{ml}$ as determined in animal studies. This dose was associated with moderately increased systolic blood pressure $(\sim 30 \mathrm{mmHg})$, which was responsive to antihypertensive agents, and neurologic adverse experiences (mild sedation and confusion) that were easily tolerated by patients. However, no suggestion of treatment effect was found between the groups.

Based on these results, a nested phase 2/phase 3 study was performed evaluating low-dose and high-dose Cerestat regimens compared to placebo. ${ }^{29}$ Patients with clinical diagnosis of ischemic stroke were randomized to 1 of 3 treatment arms within $6 \mathrm{~h}$ of symptom onset. Phase 3 enrollment was terminated early, based on analysis of the phase 2 data that revealed an increase in mortality within the Cerestat cohort. Analysis of available phase 3 data (628 patients) showed no difference in 90-day outcome measured by modified Rankin Scale (mRS) among the 3 groups. The difference in 90-day mortality was not significant; however, there was a marginally increased mortality at 120 days in the high-dose group. Other secondary analyses showed a significant difference favoring placebo over high-dose Cerestat in multiple outcome measures. Based on the evidence, Cerestat is not efficacious within $6 \mathrm{~h}$ of onset and may be harmful at higher doses.

Magnesium $\left(\mathrm{Mg}^{2+}\right)$ is theoretically an ideal neuroprotectant based upon its diverse mechanisms of action, low cost, ease of administration, wide therapeutic index, good blood-brain barrier (BBB) permeability, and established safety profile. $\mathrm{Mg}^{2+}$ ions endogenously function as a physiologic voltage-dependent block of the NMDA receptor ion channel and inhibitor of ischemia-induced glutamate release. ${ }^{30}$ In addition to these anti-excitotoxic actions, $\mathrm{Mg}^{2+}$ antagonizes voltage-gated $\mathrm{Ca}^{2+}$ channels of all types, promotes vasodilation, inhibits the inflam- 
matory response, and calcium-mediated activation of intracellular enzymes. ${ }^{31}$ Preclinical models show that $\mathrm{MgSO} 4$ reduces infarct volume with a dose-response relationship demonstrated within easily achieved serum levels $(1.49 \mathrm{mmol} / \mathrm{l})$ even $6 \mathrm{~h}$ after stroke. ${ }^{32}$ This model refreshingly mimics the clinical reality in which patients present for treatment $h$ after the onset of ischemia. However, the benefit of $\mathrm{Mg}^{2+}$ has only been shown in some labs in some models.

Several pilot studies have already demonstrated the safety and tolerability of intravenous $\mathrm{Mg}^{2+}$ in acute ischemic stroke patients. ${ }^{33,34}$ Administration of $\mathrm{MgSO} 4$ as loading dose followed by a 24-h continuous infusion has been studied in over 3,000 stroke patients within $48 \mathrm{~h}$ with no significant adverse events. The majority of these studies have not revealed significant hypotension or hyperglycemia that were experienced in some preclinical evaluations of $\mathrm{MgCl}^{35}$ The majority of reported adverse events were the expected complications of the initial stroke and did not differ from placebo. A dose optimization study identified a dose (16 mmol bolus, 24-h continuous infusion of $65 \mathrm{mmol}$ ) capable of achieving the minimum neuroprotective serum levels in all patients while producing no adverse events. ${ }^{34}$ A systematic review of four phase 2 clinical trials disclosed an insignificant, $8 \%$ absolute reduction in the combined endpoint of death or functional dependence. ${ }^{30}$

One of the largest impediments to translating experimental efficacy to a clinical reality is the delayed administration of potentially cytoprotective therapies. Ongoing trials of magnesium administration have been designed to specifically address this issue. The FAST-MAG (Field Administration of Stroke Therapy-Magnesium) pilot study was an open-label evaluation of the safety and feasibility of paramedic-initiated magnesium therapy to stroke patients identified in the field by the Los Angeles Prehospital Stroke Screen (LAPSS). ${ }^{36}$ The average time to treatment was only 23 min from arrival of Emergency Medical Services on the scene, and median time to treatment from symptom onset was 100 min with $25 \%$ of patients treated within $1 \mathrm{~h}$, the shortest onset-to-treatment interval reported to date. Greater than two-thirds of patients had a good functional outcome.

Currently, a phase 3 multicenter, randomized, placebocontrolled trial will soon begin enrolling patients to evaluate the efficacy of field-administered, hyperacute $\mathrm{Mg}^{2+}$ therapy within $2 \mathrm{~h}$ of stroke onset. Additionally, the IMAGES Study Group is conducting a large phase 3 trial of $\mathrm{MgSO} 4$ administered within $12 \mathrm{~h}$ of onset designed with sufficient statistical power to detect only a 5.5\% absolute difference in death or dependence. Rigorous trial design has employed a randomization algorithm that maintains balanced group-allocation of patients based on prognostic variables including age, laterality of stroke, time-to-randomization, and Oxfordshire Community
Stroke Project classification. This study represents the single largest cytoprotective study to date and has enrolled over 1,800 patients, nearly half of which have been treated within $6 \mathrm{~h}$ of onset. An IMAGES sub-study will employ magnetic resonance imaging (MRI) as a biological surrogate for neuroprotective efficacy.

In summary, while preclinical studies of competitive and noncompetitive NMDA antagonists suggest that they can effectively protect penumbral regions, clinical studies have thus far been disappointing. Trial design, lacking forced time-to-treatment stratification, and patient selection criteria for stroke homogeneity, may have contributed to these results. As with calcium antagonists, achieving neuroprotection by blocking glutamate-induced damage means interrupting events that are triggered almost immediately after the onset of ischemia so that the time to treatment from onset must be brief. This narrow time-window, seen in all animal studies, was ignored in all clinical trials of these drugs except for the FAST-MAG trial. The negative clinical results with NMDA antagonists may also be attributed to the doselimiting phencyclidine-like side effects preventing achievement of therapeutic brain levels. An understanding of the clinically apparent neurotoxicity of NMDA antagonists involves a condition described as NMDA receptor hypofunction. NMDA antagonists have been shown to induce large vacuoles within the adult rodent brain that may signify irreversible damage. ${ }^{37}$ Recent molecular experiments have uncovered that an indirect complex network disturbance is responsible for the NMDA receptor hypofunction. Finally, a model of immature rodents demonstrates that administration of NMDA antagonists during the period of synaptogenesis triggers diffuse apoptotic degeneration throughout the brain. ${ }^{38}$

These complex interactions indicate the potential problems with using drugs that target specific neurotransmitter function. Attempts have been made to develop strategies inhibiting glutamate-induced damage while avoiding the toxicity profile of direct NMDA receptor antagonism. Clinical trials of these and more "downstream" agents will now be discussed.

\section{Agents acting indirectly on glutamate}

Eliprodil, an antagonist of the polyamine site of the NMDA receptor, has been evaluated in phase 2 and phase 3 trials of acute stroke patients. However, these data remain unpublished and further investigation has stopped due to an unsatisfactory risk/benefit ratio. ${ }^{39}$

GV150526 (gavestinel) is a novel glycine site antagonist at the NMDA receptor complex, which exhibits neuroprotective effects in experimental stroke models at established plasma levels (10 to $30 \mu \mathrm{g} / \mathrm{ml}$ ) with a paucity of toxicity and an extended time-window $(6 \mathrm{~h}) .{ }^{40} \mathrm{~A}$ phase 2 randomized, placebo-controlled, two-part ascending dose trial evaluated the safety, tolerability, and 

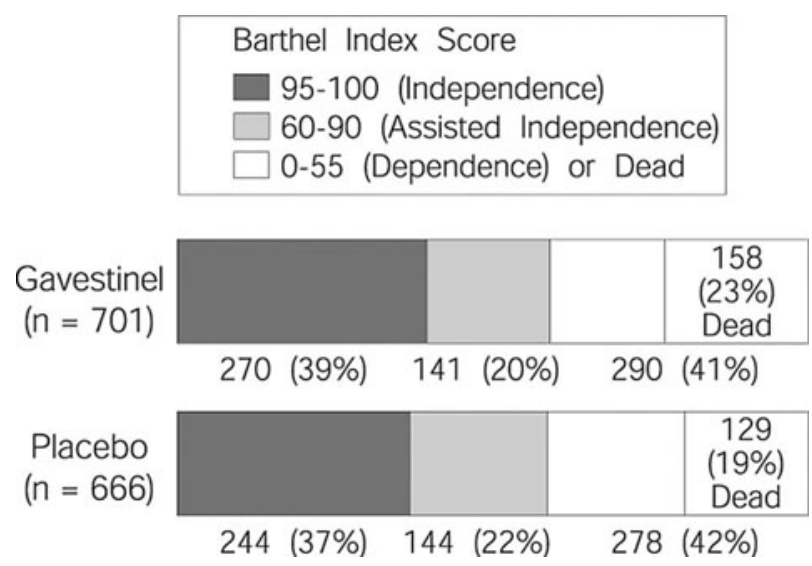

FIG. 2. Barthel Index Score results of the GAIN Americas trial of Gavestinel vs. placebo in acute stroke patients. From JAMA 285:1719. Copyright (C) 2001, American Medical Association. All rights reserved.

pharmacokinetics of a gavestinel loading dose followed by continuous infusion within $12 \mathrm{~h}$ of stroke onset. ${ }^{41}$ The first part involved administration of escalating loading doses to determine the maximal tolerated dose of gavestinel. In the second part, the maximum tolerated loading dose from part one $(800 \mathrm{mg}$ ) was followed by five maintenance infusions every $12 \mathrm{~h}$. GV150526 produced no increased hemodynamic or neuro-psychiatric events compared to placebo. No consistently reported or doserelated side effects, serious adverse events or mortality were attributed to drug administration. Mild anemia and asymptomatic, transient dose-dependent elevations in liver function tests were observed. Significantly higher serum glucose levels were observed in patients receiving maintenance gavestinel and the degree of hyperglycemia was correlated to the volume of dextrose diluent used for infusion. All loading dose regimens easily achieved plasma concentrations exceeding the predicted therapeutic levels from animal studies, and maintenance infusions of 200 or $400 \mathrm{mg}$ b.i.d. sustained this neuroprotective level. An 800-mg loading dose followed by five 200-mg infusions twice daily was identified as the optimal dosage to be used for phase 3 efficacy studies.

Subsequently, two large phase 3 randomized placebocontrolled, double-blind trials failed to demonstrate the efficacy of gavestinel despite adequate powering to detect even small differences. The GAIN Americas trial randomized 1,367 patients within $6 \mathrm{~h}$ of stroke onset and concomitant treatment with intravenous TPA was allowed in eligible patients. ${ }^{42}$ Patients were stratified at randomization by age and initial stroke severity. Mean NIHSS was 12 and median time to treatment was $5.2 \mathrm{~h}$. No statistically significant difference in mortality or 3-month outcome measures [Barthel Index (BI), mRS, or NIHSS score] was found among the groups (FIG. 2). Subgroup analysis revealed a significant treatment benefit in younger patients with mild stroke ( $\leq 75$ years, NIHSS 2-5) that persisted even after adjustment for age, baseline NIHSS, use of TPA, time to treat, and stroke subtype. However, no treatment effect was seen in either the TPA-treated patients $(n=333)$ or those treated within $4 \mathrm{~h}$ of onset $(n=244)$.

The GAIN International trial recruited 1,804 patients within $6 \mathrm{~h}$ of stroke onset and used the same dosing regimen and stratified randomization schema. ${ }^{43}$ The primary efficacy measure, survival combined with 3-month, BI, was analyzed in only the ischemic stroke population. Secondary endpoints included BI, NIHSS score, mRS, death within 3 months, and global statistical test of combined neurological status at 3 months. Gavestinel had no effect on primary or secondary outcome measures compared with placebo when baseline NIHSS score and age were included as covariates in proportional odds models. Minor adverse events were seen more commonly in the
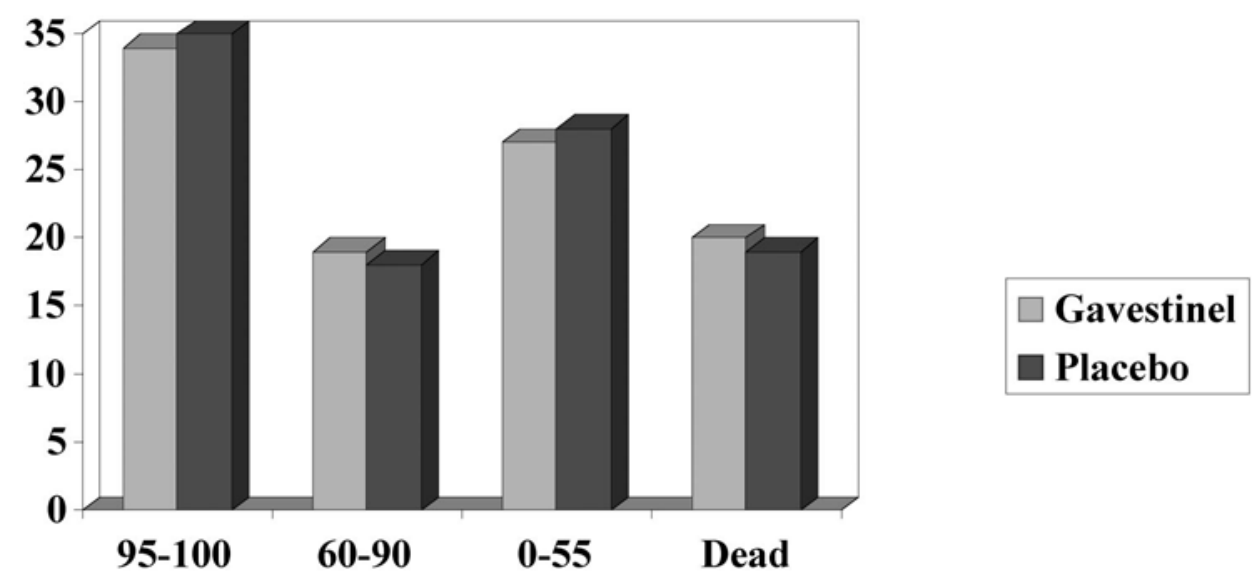

Barthel Index

FIG. 3. Barthel Index Score results of the GAIN Americas trial of Gavestinel vs. placebo in acute stroke patients. Reprinted with permission from Elsevier (The Lancet, 355:1949-1954, 2000). 
gavestinel group, but no significant differences were found in serious adverse events (FIG. 3).

The neutral results of the large gavestinel trials are disconcerting for several reasons. First, the clinical testing closely mimicked the experimental models exhibiting neuroprotection even after $6 \mathrm{~h}$ of ischemia. Second, these trials incorporated an adequate number of patients to exclude a clinically significant benefit of gavestinel, a point that has been used to criticize previous trials. Additionally, these trials appropriately stratified patients according to baseline stroke severity and age, factors that may otherwise cause imbalances within treatment and placebo groups and produce confounding results. Lastly, "supra-therapeutic" neuroprotective levels were achieved producing only minimal and tolerable side effects. Therefore, unlike other modulators of glutamate activity, gavestinel doses were not limited by intolerability of "therapeutic" doses. The cause of the neutral results with gavestinel remains to be explained. It is possible that the time window to effectively antagonize glutamate is simply less than $6 \mathrm{~h}$, or that the neuroprotective benefit of infarct size reduction in animals does not translate into improved functional outcome measured in clinical trials. Just as likely, however, expectations with gavestinel were over-inflated because only positive preclinical results were published (it is common that negative results in animal studies go unreported). Mild beneficial effects were only seen in carefully standardized stroke models that do not reflect the heterogeneity of stroke patients where more robust efficacy would be needed to achieve clinical significance.

Blockade of glutamate-activated AMPA receptors represents another target of cytoprotection with several advantages over NMDA receptor antagonism including potential protection of both cortical gray matter and subcortical white matter regions, and reduction of secondary activation of NMDA receptor and voltage-gated calcium channels. One promising AMPA antagonist, YM872, has demonstrated reduced infarct volume comparable to NMDA receptor antagonists in animal models. ${ }^{44}$

Enrollment has just been terminated prematurely in two concurrent YM872 clinical trials, the ARTIST (AMPA Receptor Antagonist Treatment in Ischemic Stroke) trials, based on an interim futility analysis. These multicenter, randomized, double-blind, placebo-controlled trials were designed to "fill in the gaps" left by past neuroprotection trials-combination of reperfusion and neuroprotection strategies, and use of a biologic marker of efficacy. ARTIST+ compared the efficacy of YM872 plus TPA to that of placebo plus TPA. Preclinical data have demonstrated that co-administration of TPA and YM872 within $2 \mathrm{~h}$ of stroke imparts a greater degree of cytoprotection than either agent alone. ${ }^{45} \mathrm{~Pa}$ tients with acute hemispheric ischemic stroke and a moderate-to-severe deficit treated with standard protocol
TPA were eligible. The planned enrollment was 600 patients; over 400 patients were enrolled. The drug was started before the end of TPA infusion and continued for $24 \mathrm{~h}$. Primary efficacy/outcome measures included neurological function and disability scales.

The second trial, ARTIST MRI, evaluated the safety and potential efficacy of YM872 administered to stroke patients within $6 \mathrm{~h}$ of onset using MRI as a surrogate marker of outcome. Baseline ischemic lesion volume on diffusion-weighted imaging was compared to final lesion volume on T2-weighted MRI to detect effect of YM872 on lesion growth. The abandonment of these very welldesigned trials is disappointing. Further investigation of YM872 is not planned at this time.

Inhibitors of glutamate release are a heterogeneous group of agents, including anticonvulsants and antidepressants. The proposed mechanism of action for these drugs is ion channel blockade.

The anti-epileptic drug lamotrigine inhibits glutamate release and has shown beneficial effects in a rodent model of focal cerebral ischemia when administered immediately after ischemia ${ }^{46}$; however, a 2-h delay of treatment produced no effect on infarct volume or neurological outcome in two models. ${ }^{47}$ To our knowledge, no clinical stroke trials of lamotrigine have been performed. Similarly, a derivative of lamotrigine, sipatrigine (BW619C89), is a use-dependent sodium channel antagonist that inhibits presynaptic glutamate release. It has been shown to decrease glutamate release during ischemia $^{48}$; however, like lamotrigine it reduced infarct volume only when administered at onset of ischemia. ${ }^{49} \mathrm{Si}$ patrigine has been evaluated in phase 2 clinical trials in patients within $12 \mathrm{~h}$ of stroke onset. ${ }^{50}$ Like Selfotel, continuous infusion of sipatrigine produced intolerable neuro-psychiatric effects while showing no trend to improved outcomes in a small cohort of 27 patients. A subsequent two-part trial evaluating the maximum tolerated dose and efficacy of sipatrigine was halted early by the trial sponsor and further clinical development of the drug for stroke has ceased. ${ }^{51}$

Preclinical studies have shown that phenytoin can reduce neuronal injury, possibly by inhibiting spreading electrical depolarization in penumbral regions and thereby reducing post-ischemic glutamate release. Fosphenytoin, an aqueous-soluble rapidly injectable pro-drug of phenytoin, is another sodium channel blocker. A multicenter combined phase $2 / 3$ evaluation of intravenous fosphenytoin within $4 \mathrm{~h}$ of acute stroke was terminated prematurely after interim analysis of 462 enrolled patients showed no difference between placebo and fosphenytoin in any of the functional or disability outcomes. ${ }^{52}$

A novel calcium-sensitive maxi-potassium channel opener, BMS-204352, causes neuronal hyperpolarization, decreased calcium influx and glutamate release. ${ }^{53} \mathrm{~A}$ phase 3 trial (POST) of 1978 patients with moderate-to- 
severe cortical strokes treated within $6 \mathrm{~h}$ of onset failed to show any significant beneficial effect when compared to placebo, though these results have not yet been published. A sub-study evaluated the change in lesion volume on MRI over a 12-week period as a biologic surrogate outcome marker. ${ }^{54}$

Lubeluzole is a novel benzothiazole compound that has emerged as a neuroprotective agent in animal models of focal ischemia. ${ }^{55-57}$ In some laboratories, lubeluzole has achieved reduction of infarct volume and improved neurologic outcome in animal models even when administered up to $6 \mathrm{~h}$ after infarct induction. ${ }^{55}$ There are several putative mechanisms by which lubeluzole protects the penumbral region in these models. First, lubeluzole normalizes neuronal activity in the peri-infarct region by inhibiting glutamate release possibly via blockade of non-L-type calcium channels. ${ }^{58}$ Additionally, blockade of sodium channels and taurine release by lubeluzole suggests that it may reduce osmoregulatory stress in the peri-infarct zone. Finally, lubeluzole diminishes nitric-oxide-related neurotoxicity. ${ }^{59}$

A phase 2 clinical trial of lubeluzole in acute ischemic stroke suggested that lubeluzole lowers mortality and disability in some patients. ${ }^{60}$ Two dosing regimens were compared to placebo. Subjects clinically diagnosed with acute ischemic stroke in the middle cerebral artery territory were treated within $6 \mathrm{~h}$ of onset of symptoms. The low-dose lubeluzole group experienced no excess of cardiac arrhythmias compared to placebo, although there was a higher incidence of ventricular fibrillation in the high-dose lubeluzole group. Overall mortality was $6 \%$ for the lower dose regimen compared to $18 \%$ and $35 \%$ in the placebo and higher dose regimen of lubeluzole, respectively. The trial was terminated prematurely when a multivariate logistic regression analysis found this significant imbalance in the 28-day mortality favoring treatment with the low-dose regimen. The excess mortality in the higher dose group was partially due to imbalanced randomization with more severe strokes in this group. When multivariate regression accounted for stroke severity, high-dose treatment had no effect on mortality. The BI tended to be higher in the lower dose lubeluzole group, but no significant differences in efficacy measures were found among the groups.

Based on the results of this pilot study, subsequent phase 3 randomized, multicenter, double-blind, placebocontrolled trials adopted the low-dose regimen to test the efficacy of lubeluzole in acute ischemic stroke patients. However, it is essential to note that the low-dose regimen produced a subtherapeutic mean plasma concentration. ${ }^{61}$

Three large-scale, multicenter, double-blind, placebocontrolled randomized phase 3 trials of low-dose lubeluzole in stroke patients have produced conflicting results. The European and Australian trial randomized 725 patients within $6 \mathrm{~h}$ of onset and demonstrated similar overall mortality, adverse events and clinical outcome between all placebo and lubeluzole-treated patients. ${ }^{62}$ However, an unplanned post hoc analysis found that lubeluzole treatment decreased mortality among patients with mild to moderate stroke measured by the Clinical Global Impression rating. The North American trial included 721 patients within $6 \mathrm{~h}$ of moderate to severe hemispheric stroke. ${ }^{63}$ The mean time to treatment was $4.7 \mathrm{~h}$. The degree of functional recovery (Barthel Index) and disability (mRS) at 3 months significantly favored lubeluzole over placebo after controlling for appropriate covariates. The odds of favorable outcome were $38 \%$ higher with lubeluzole according to the global test statistic. This study also found a non-significant improvement in mortality in the lubeluzole group and confirmed the safety of the low-dose regimen with no significant differences in cardiac-related complications or adverse events. Finally, the third efficacy trial randomized 1,786 total patients including a core stroke group consisting of patients with ischemic stroke, excluding patients aged $>75$ years with severe strokes, treated within 0 to $6 \mathrm{~h}$. Only the core stroke group was used in the primary efficacy analyses. Lubeluzole had no significant effect on mortality or 12-week functional status in the core stroke group. Similar neutral results were found in the nontarget population including all treated patients. Lubeluzole-treated patients experienced more cardiac events including atrial fibrillation and QT interval prolongation but this was not associated with increased mortality.

Finally, lubeluzole was the first potentially neuroprotective agent to be evaluated in a dedicated combination trial with TPA. Patients who qualified for and received intravenous TPA within $3 \mathrm{~h}$ of symptom onset were randomly allocated $1: 1$ to lubeluzole or placebo. ${ }^{64}$ Infusion of medication was started before the end of the 1-h TPA infusion. Eighty-nine patients were enrolled before the early trial termination based on the negative results of the previously described concurrent lubeluzole phase 3 trial. In the enrolled patients (45\% of the planned population), TPA and study drug were administered at a mean of 2.5 and $3.2 \mathrm{~h}$ from symptom onset, respectively. There were no significant differences in mortality $(26 \%)$, intracerebral hemorrhage $(10 \%)$, serious adverse events $(51 \%)$ or functional outcomes (Barthel Index) between lubeluzole and placebo. These results demonstrate the safety and feasibility of linking ultra-early neuroprotection with thrombolysis, however the premature stoppage of enrollment led to a study underpowered to detect efficacy.

A recent systematic review of five randomized trials, including a total of 3,510 patients, found no evidence that lubeluzole given at any dose reduced the odds of death or dependency at the end of follow-up (odds rated $1.03,95 \%$ CI 0.91-1.19). ${ }^{65}$ However, at any given dose, 
lubeluzole was associated with a significant excess of cardiac conduction disorders.

There are several reasons that the lubeluzole trials may have failed to show efficacy. As with many other agents, the time interval from stroke onset to drug administration is most likely too long to meaningfully inhibit glutamate release and action. Although an extended 6-h time window for efficacious treatment has been reported, other animal models have failed to replicate the efficacy of lubeluzole initiated $30 \mathrm{~min}$ after ischemia. The discrepant results between the North American and European trials may be in part due to time interval to drug initiation. In the North American trial the mean time interval was $4.7 \mathrm{~h}$. Although a similar mean is not reported by the European trial, over $80 \%$ of patients were treated beyond $4 \mathrm{~h}$ potentially leading to lessened efficacy. Also, doselimiting side effects, primarily cardiac, led to a narrow therapeutic index with resultant serum levels below the minimum neuroprotective level reported in animals. A preliminary analysis of the pharmacokinetics/dynamics in the European trial found a trend toward improved functional outcome (mRS) in patients with a plasma concentration $>70 \mathrm{ng} / \mathrm{ml}$. Variability in achieved plasma levels may have occurred to account for conflicting reports of efficacy. Although the combination trial of lubeluzole and TPA required treatment within $4 \mathrm{~h}$, its early termination led to underpowered sample size to detect efficacy.

\section{Other neurotransmitter modulators}

Serotonin agonists may exert cytoprotection via several actions at pre- and post-synaptic 5 - $\mathrm{HT}_{1 \mathrm{~A}}$ receptors, including neuronal membrane hyperpolarization with reduction in glutamate release ${ }^{66}$; these agents may also inhibit apoptosis. $^{67}$

One small trial of 49 acute stroke patients failed to show the efficacy of a serotonin reuptake inhibitor, trazodone, on mortality or neurologic deficit compared to placebo. ${ }^{68}$ The neuroprotective efficacy, safety and tolerability of another serotonergic agent are being studied in ongoing acute stroke trials. Repinotan (Bay x 3702) is a serotonin agonist of the $5 \mathrm{HT}_{1 \mathrm{~A}}$ subtype that produces $55 \%$ reduction of infarct volume in experimental models of permanent focal ischemia. ${ }^{69} \mathrm{~A}$ phase 2 trial of repinotan identified $1.25 \mathrm{mg}$ /day given for 3 days as a dose that is well tolerated by stroke patients and may improve neurological outcome at 3 months ${ }^{70}$ A double-blind, placebo-controlled phase 3 trial is currently randomizing patients with moderate to severe stroke (NIHSS 8-23) to placebo or repinotan within $6 \mathrm{~h}$ of symptom onset. Treatment with intravenous thrombolysis is allowed. The drug is administered at a rate of $1.25 \mathrm{mg} /$ day for $72 \mathrm{~h}$ and doses are titrated to a targeted blood level of 5 to 20 $\mathrm{mcg} / \mathrm{l}$. The primary outcome measure is the Barthel In- dex at 3 months. Planned enrollment for this phase 3 trial is 600 patients. $^{71}$

A safety and efficacy study of a novel neurotransmitter modulator, ONO-2506, is currently recruiting stroke patients within $6 \mathrm{~h}$ onset of a radiographically confirmed cortical infarct. The proposed mechanism of action is modulation of glutamate transporter uptake capacity and expression of GABA receptors. ${ }^{72}$

The endogenous opioids act at the kappa opioid receptor as excitatory neurotransmitters and potentiators of ischemic injury. Opiate receptor antagonists have exhibited cytoprotective activity in preclinical focal and global models of ischemia. ${ }^{73-75}$ Several small trials of naloxone have failed to conclusively show efficacy in acute ischemic stroke. ${ }^{76-80}$ The equivocal results are likely due to under-powering of these small studies to detect small but significant treatment effects. Also, naloxone is relatively nonspecific for the kappa receptor. Recently, attention has shifted to nalmefene, an opiate antagonist that has relatively pure activity at the kappa receptor.

In a phase $2 \mathrm{a}$ trial, nalmefene $(0.1 \mathrm{mg} / \mathrm{kg})$ administered within $6 \mathrm{~h}$ of stroke onset was found to be tolerable and possibly efficacious. ${ }^{81}$ Although no overall treatment effect was observed, a subgroup analysis suggested that nalmefene may confer a beneficial effect in young patients $(<70$ years $){ }^{82}$

Based on phase 2 data, a phase 3 trial was designed to study the safety and efficacy of $60 \mathrm{mg}$ of nalmefene administered as a bolus dose followed by continuous infusion over $24 \mathrm{~h} .{ }^{83} \mathrm{~A}$ total of 368 patients were randomized within $6 \mathrm{~h}$ of stroke onset. This sample size was constructed to detect a $15 \%$ improvement with treatment. Concomitant use of TPA was allowed; however, that population was analyzed as a separate subgroup $(n=38)$ and was therefore excluded from the intention-to-treat analysis. There was no significant treatment effect on 3-month outcome on any of the planned analyses, including secondary analyses in young patients and thrombolytic-treated patients. However, the small number of patients within both of these subgroups increases the likelihood of excluding a treatment effect that is actually present. Although the nalmefene-treated patients experienced more nausea, there was not a significant increased incidence of neuro-psychiatric effects.

There are several potential explanations for the negative results of the opioid antagonist trials. As with other upstream modulators of excitotoxicity, delayed treatment may not confer neuroprotection because the pivotal steps in the cascade have already occurred by time of treatment. Also, the trial design did not enforce recruitment of adequate numbers of patient into the subgroups most likely to derive benefit (young patients, moderate-tosevere deficits, thrombolytic-eligible) resulting in an under-powered design. Lastly, no pharmacokinetic studies were performed so the adequacy of dosage is unknown. 
Enhancement of GABA-induced inhibition may be a useful target of cytoprotection. Clomethiazole is a GABA agonist that theoretically prevents damage due to excessive excitatory neurotransmitters by enhancing inhibition at the $\mathrm{GABA}_{\mathrm{A}}$ receptor level. ${ }^{84}$ The GABA receptor activation causes increased chloride conductance and membrane hyperpolarization that depresses neuronal depolarization and excitability. ${ }^{85}$ Clomethiazole has been shown to exhibit neuroprotection in several focal ischemia models. ${ }^{86,87}$

A dose-escalation trial demonstrated an acceptable safety profile in acute stroke patients with dose-related sedation observed. ${ }^{88}$ In this study, $75 \mathrm{mg} / \mathrm{kg}$ administered as a continuous infusion over $24 \mathrm{~h}$ achieved plasma concentrations comparable to those producing experimental neuroprotection. ${ }^{89}$ Therefore this dose was chosen for phase 3 trials.

The Clomethiazole Acute Stroke Study (CLASS) evaluated clomethiazole in a randomized, placebo-controlled manner in hemispheric ischemic stroke patients with a moderate-to-severe deficit within $12 \mathrm{~h}$ of onset. ${ }^{90}$ The study was powered to detect a $9 \%$ difference in the percent of patients reaching relative functional independence with treatment. Efficacy analysis of 1,353 patients revealed a non-significant $1.2 \%$ difference favoring clomethiazole in achievement of functional independence assessed by Barthel Index. Sedation was the most common adverse event and led to withdrawal of treatment in $15.6 \%$ patients. There was no difference in incidence of cardiopulmonary conditions or progressive stroke between the groups. Onset-to-treatment interval had no effect on recovery between the groups after controlling for age and baseline stroke severity. Subgroup analyses found a significant beneficial effect of clomethiazole in two overlapping groups, those with severe baseline neurological deficit and those classified as having a total anterior circulation stroke. This suggests that patients with the largest strokes may have a larger penumbra that may be salvaged by cytoprotective therapy. ${ }^{91}$

The Clomethiazole Acute Stroke Study in Ischemic Stroke (CLASS-I) was designed to test the hypothesis generated by the previous CLASS trial: clomethiazole is effective in patients with large ischemic anterior circulation strokes. ${ }^{92}$ Ischemic stroke patients with evidence of higher cortical dysfunction plus visual field and motor deficit were randomized within $12 \mathrm{~h}$ of onset to placebo or clomethiazole. The mean NIHSS score was 16.9 and the mean time to treatment was $7.7 \mathrm{~h}$. The population kinetic assay produced a therapeutic plasma concentration during the 24-h infusion. There was no evidence of efficacy on any of the outcome variables including NIHSS score, BI, mRS, and 30-day lesion volume.

The absence of treatment effect occurred despite adequate trial design based on sound preclinical data, appropriate patient selection, and adequate drug concentra- tions. Once again, the lack of efficacy may be based on the prolonged time window of $6 \mathrm{~h}$ or the inadequate prediction of human pharmacokinetics based on rodent data.

A large international trial is recruiting patients to study the effect of diazepam, a benzodiazepine with established GABA-ergic activity, within $12 \mathrm{~h}$ of stroke onset. There are no preliminary results thus far. ${ }^{93}$

In summary, a large number of drugs that target glutamate and other neurotransmitter function have shown preclinical efficacy but have failed in clinical trials. A major factor has been side effects that limit dose, but even those that have achieved therapeutic dose ranges and have been sufficiently powered (GAIN and CLASS) have been neutral or negative. Currently, the best remaining hope for this strategy is with ongoing trials of magnesium. However, taken in their entirety, the data suggest that monotherapy targeting a single neurotransmitter function may not provide sufficient neuroprotection to provide clinically meaningful benefit.

\section{Free radical scavengers, adhesion molecule blockers, steroids, and other anti-inflammatory strategies}

Other strategies of neuroprotection attack later stages of the ischemic cascade. Nitric oxide (NO) synthesis is induced by stimulation of glutamate receptors, and NO in turn has a number of complex actions relevant to ischemia and cell injury. Endothelium-derived NO causes vasodilatation beneficial to ischemic brain, but neuronal NO generates oxygen free radicals toxic to cells. In animal models of stroke, NO synthase inhibitors have complex effects befitting the dual role of NO in cerebral ischemia. The usefulness of NO modulation in stroke likely will hinge on the ability to favorably manipulate the beneficial and deleterious effects of NO.

Reactive oxygen intermediates play a role in ischemic tissue damage and represent another later target for cytoprotection. Tirilazad mesylate is a 21-aminosteroid free radical scavenger and potent membrane lipid peroxidation inhibitor that has shown neuroprotective promise in focal ischemia and subarachnoid hemorrhage models. ${ }^{94,95}$ This agent protects the microvascular endothelium and maintains intact BBB and cerebral autoregulatory mechanisms. Unfortunately, this agent has limited penetration into the brain parenchyma and may lead to unsatisfactory efficacy in stroke, as demonstrated by clinical trials to date. ${ }^{96}$

A sequential dose-escalation trial determined that tirilazad doses of up to $6 \mathrm{mg} / \mathrm{kg} / \mathrm{day}$ for 3 days are safe and well tolerated when administered within $6 \mathrm{~h}$ of acute stroke. ${ }^{97}$ A phase 3 randomized trial of tirilazad within $6 \mathrm{~h}$ of stroke onset was terminated prematurely after a pre-planned interim analysis of 660 patients determined futility of continued enrollment. ${ }^{98}$ No statistically signif- 
icant difference was found in the proportion of patients achieving a favorable outcome due to tirilazad treatment administered at a median of $4.3 \mathrm{~h}$. The lack of efficacy in this trial was in part ascribed to inadequate dosing, especially in women, and a second tirilazad trial was designed using a higher dosing regimen. ${ }^{99}$ This trial was discontinued prematurely for safety concerns raised by a concurrent European trial, despite trends toward reduced mortality and dependence in both men and women. A recent systematic review of six randomized, controlled trials ( $>1,700$ patients) included previously unpublished data from two large negative European trials. ${ }^{100}$ This review found that tirilazad actually increases death and disability by one-fifth. Additionally, subgroup analyses demonstrated a significantly worse outcome in women and patients treated with lower doses of tirilazad, as well as trends for worse outcome in patients with mild to moderate stroke.

A sub-study of the European trials determined that early tirilazad treatment $(<6 \mathrm{~h})$ had no significant effect on infarct volume in the whole population. However, post hoc analysis found that men with cortical infarcts have a significant reduction in infarct volume; this beneficial effect was no longer significant after adjustment for age and stroke severity. ${ }^{101}$

It is still unclear if tirilazad exhibits not only a lack of neuroprotection but may induce worsening within specific populations of patients. Potential reasons for these results include controversial results of preclinical studies, ${ }^{102}$ delayed drug administration (more than $75 \%$ patients treated after $3 \mathrm{~h}$ ), thrombophlebitis causing a systemic inflammatory state and inadequate BBB permeability. Finally it is possible that generation of free radicals plays a positive role in the recovery of stroke patients.

Ebselen is another type (seleno-organic) of antioxidant that potentially inhibits lipid peroxidation through multiple mechanisms. These include inhibition of lipoxygenase within the arachidonate cascade, blocked production of superoxide anions by activated leukocytes, ${ }^{103}$ inhibition of inducible NO synthase, ${ }^{104}$ and glutathione-like inhibition of membrane lipid peroxidation. ${ }^{105}$ An unpublished phase $2 \mathrm{~b}$ dose-escalation trial determined $300 \mathrm{mg} /$ day to be the optimal dose. A single randomized efficacy trial has shown that early treatment with ebselen improved outcome after acute ischemic stroke. ${ }^{106}$ In this trial, ebselen was administered orally to patients within $48 \mathrm{~h}$ of ischemic stroke onset. There was no statistically significant difference in mortality. Intention-to-treat analysis demonstrated that ebselen treatment achieved a significantly better outcome at 1 month, but only a trend to improvement was observed at 3 months. Although the ebselen group included slightly more patients with mild impairment than the placebo group, the difference was not significant and the efficacy of ebselen was also demonstrated in patients with moderate-to-severe deficits.
Ebselen treatment within $24 \mathrm{~h}$ significantly improved the likelihood of good recovery on the Glasgow Outcome Score compared to placebo ( $42 \%$ versus $22 \%, p=$ 0.038), whereas treatment after $24 \mathrm{~h}$ led to no significant differences between the groups. Based on the results of this adequately powered trial, ebselen is felt to be safe and possibly efficacious.

Currently, a multicenter phase 3 ebselen trial is recruiting patients. This trial will determine the efficacy of ebselen in patients with clinical and radiographic cortical stroke within $24 \mathrm{~h}$ of symptom onset. Planned enrollment is 390 patients and primary outcome is Glasgow Outcome Score at 3 months.

Free radical production occurs during ischemia and reperfusion and contributes to the neuronal injury after stroke. Several nitrone free radical trapping agents (spintrap agents) have demonstrated neuroprotection in both transient and permanent focal ischemia rodent models. ${ }^{107,108}$ NXY-059 (disodium 4-[(tert-butylimino) methyl] benzene-1,3-disulfonate $N$-oxide) is a novel nitrone-based compound that has free radical trapping properties. The neuroprotective efficacy of NXY-059 is retained even when given up to $5 \mathrm{~h}$ after onset of ischemia. In a primate model of permanent focal ischemia, NXY-059 significantly decreased neurological disability and reduced infarct volume in both cortical and subcortical regions. ${ }^{109}$ Pharmacokinetic studies reveal that NXY-059 produces dose-dependent neuroprotection at unbound plasma concentrations of 50-150 $\mu \mathrm{mol} / 1 .{ }^{110}$

A randomized, double-blind, placebo-controlled phase 2 trial evaluated the tolerability and pharmacokinetics of two NXY-059 dose regimens in stroke patients. ${ }^{111} \mathrm{~Pa}-$ tients were randomized within $24 \mathrm{~h}$ of stroke onset to placebo, low-dose or high-dose NXY-059. Treatment was administered as a loading dose over $1 \mathrm{~h}$ followed by a continuous infusion over $71 \mathrm{~h}$. The infusion rate was reduced by $50 \%$ in patients with impaired renal function (calculated creatinine clearance 50 to $59 \mathrm{ml} / \mathrm{min}$ ). These dose regimens were designed to reach a target unbound plasma concentration $>40 \mu \mathrm{mol} / \mathrm{l}$ that has demonstrated neuroprotection in rodents. One hundred fifty patients were enrolled at a mean of $15 \mathrm{~h}$ after symptom onset. No increase in overall incidence of adverse events occurred in the NXY-059 group compared to placebo. However, more severe adverse events and deaths occurred within the low-dose NXY-059 in accordance with the increased number of primary intracerebral hemorrhages within this group. Common adverse events included hyperglycemia, headache, and fever, but were not related to treatment. The mean unbound plasma concentrations were 25 and $45 \mu \mathrm{mol} / \mathrm{l}$ in the low- and high-dose groups respectively.

Similar to other phase 2 studies, these concentrations were well tolerated and below the target level. Therefore, study of higher NXY-059 doses was justified. A phase $2 \mathrm{~b} / 3$ study is planned to determine the efficacy of a 
higher dose regimen (2,264 mg loading dose, up to 947 $\mathrm{mg} / \mathrm{hr}$ infusion over $71 \mathrm{~h}$ ). Planned enrollment is 1,550 acute stroke patients within $6 \mathrm{~h}$ of stroke onset with concurrent use of intravenous thrombolytics allowed. Primary outcome measure is mRS score.

Complex inflammatory processes mediate ischemicand reperfusion-related brain injury and these represent an ideal downstream target for cytoprotection. Modulation of cytokines, inflammatory-related enzymes (NO synthase), endothelial leukocyte interactions, leukocyte activation, and gene transcription factors has been investigated in experimental models and a few clinical trials.

Various models of focal ischemia have demonstrated increased expression of leukocyte-endothelial adhesion molecules, ${ }^{112,113}$ and the absence of adhesion molecules in knock-out mice significantly reduces infarct size. ${ }^{114,115}$ Anti-adhesion molecule strategies have shown efficacy only in models of transient ischemia supporting the belief that neuroprotection will impart significant benefit only when coupled to reperfusion. ${ }^{16,117}$ Furthermore, animal studies have demonstrated that combination therapy of TPA and anti-adhesion therapy (either anti-ICAM-1 or anti-CD-18 antibody) significantly reduces infarct volume and neurologic deficit score more than either agent alone even when administered up to $4 \mathrm{~h}$ after ischemia induction. ${ }^{118}$

Although contradictory evidence for up-regulation of inflammatory adhesion molecules in ischemic stroke patients exists, the majority of studies demonstrate elevations in circulating adhesion molecules (soluble (s)ICAM-1, sVCAM-1, sP-selectin, and sE-selectin). ${ }^{119-121}$ Elevated ICAM-1 expression has been observed on microvessels within infarcts in patients surviving $15 \mathrm{~h}$ to 6 days post-stroke. ${ }^{122}$

Enlimomab is a murine monoclonal anti-ICAM-1 antibody that has undergone phase 3 testing in stroke patients. A preliminary open-label pilot dose-ranging study identified a dose that was generally well tolerated and produced the target serum level thought to be neuroprotective. ${ }^{123}$ A subsequent phase 3 trial tested the efficacy of this dosing regimen $(160 \mathrm{mg}$ on day 1 followed by a maintenance dose of $40 \mathrm{mg} /$ day for 4 days) compared to placebo in 625 ischemic stroke patients within $6 \mathrm{~h}$ of symptom onset. ${ }^{124}$ This dose achieved the target level in $96.6 \%$ of patients after the first dose, and adequate trough levels were maintained throughout the duration of treatment. Enlimomab treatment was associated with worse disability and increased mortality compared to placebo. The hazard of death averaged over the first 90 days was $43 \%$ higher in enlimomab-treated patients than placebo-treated patients. Adverse events reported more frequently by the active treatment group included fever, myocardial infarction, pulmonary edema, pneumonia, stroke progression, cardiac arrest, meningitis, cerebral edema, and intracerebral hemorrhage. Fever was re- ported twice as often in enlimomab-treated patients. However, the negative effect of treatment cannot be ascribed solely to the drug's propensity to cause fever since stroke outcome was marginally improved in febrile patients on enlimomab compared to placebo, whereas afebrile patients on enlimomab had a worse outcome.

There are several possible explanations for the negative effect of enlimomab. First, enlimomab is a different type of antibody than that used in experimental models. It is possible that murine anti-ICAM antibody led to up-regulation of endogenous adhesion molecules and precipitated a paradoxical inflammatory response. It has been shown that all enlimomab-treated patients develop anti-mouse antibodies. An experimental model was subsequently designed to mimic the negative clinical trial. Administration of this murine antibody to rats leads to production of host humoral response against the protein, activation of compliment, neutrophils, and microvascular system. ${ }^{125}$ Second, no preclinical model delayed treatment for $6 \mathrm{~h}$ or administered the drug for 5 consecutive days as in the clinical trial. Most importantly, animal studies showed no treatment benefit in permanent ischemia models. Only a minority of patients (4\% to $24 \%$ ) have spontaneous reperfusion, and hence most enrolled patients were not comparable to transient ischemia models that were associated with treatment benefit. Therefore, the rational approach to future immuno-modulatory therapies would be development of humanized anti-adhesion molecule strategy with a revised (shorter) dosing regimen and coupling to thrombolysis.

To this end, a humanized IgG1 antibody against human CD18 (Hu23F2G or LeukArrest) was developed to block leukocyte infiltration while avoiding the complications of enlimomab due to sensitization. Phase 1 and 2 data revealed no safety concerns associated with LeukArrest. A phase 3 trial enrolled patients within $12 \mathrm{~h}$ of stroke onset, allowed concomitant TPA use, and employed a reduced frequency of dosing schema. The phase 3 trial of $\mathrm{Hu} 23 \mathrm{~F} 2 \mathrm{G}$ was terminated after interim futility analysis determined that treatment was unlikely to impart significant benefit if the trial was continued. To date, the data from this trial remain unpublished.

Promising new strategies are developing to target other "downstream" events of the ischemic/excitotoxic cascade, the calcium-dependent enzymatic reactions mediating necrotic and apoptotic cell death. Theoretically, since these processes occur "later" in the cascade, the therapeutic time-window may be prolonged. Several important enzymes have been characterized as potential targets of neuroprotection. ${ }^{126,127}$ Inhibition of these enzymes may be effective in preserving the structural integrity of neurons. Multiple experimental models have demonstrated the efficacy of calpain, caspase, and protein kinase inhibitors in reducing infarct volume up to $6 \mathrm{~h}$ after onset of ischemia. ${ }^{128-131}$ The inability of these 
large protein compounds to cross the BBB has thus far limited clinical development. However novel strategies are developing to enhance delivery of neurotherapeutics to the brain.

Recently minocycline has demonstrated protective effects in hypoxic-ischemic, focal, and global ischemia models. ${ }^{132,133}$ Minocycline, a semi-synthetic secondgeneration drug of the tetracycline group, is a safe and readily available compound that exerts anti-inflammatory effects such as inhibition of microglial activation and production of other inflammation mediators. Furthermore, minocycline may inhibit the activity of matrix metalloproteinases (MMP), diminish permeability of the $\mathrm{BBB}$, inhibit caspase, inducible NO synthase (iNOS) and p38 mitogen-activated protein kinase (MAPK). ${ }^{134}$ The neuroprotective efficacy of minocycline has been demonstrated in animal models even when delayed up to $4 \mathrm{~h}$. Minocycline appears to be an ideal neuroprotective candidate based on its established safety profile, good CNS penetration, wide availability, and inexpensive cost, and therefore deserves evaluation in clinical trials of acute ischemic stroke.

FK506 (Tacrolimus) has been widely used for prevention of transplant organ rejection, and is now being investigated as a potential neuroprotectant based on its immunosuppressive properties. FK506 suppresses the calcium-dependent signal transduction pathway that promotes proliferation of helper $\mathrm{T}$ cells by inhibition of calcineurin. ${ }^{135}$ Apoptotic cell death is also attenuated by FK506. ${ }^{136}$ Multiple animal models demonstrate the neuroprotective effects of FK506 by reduced infarct volume both histologically and radiographically. ${ }^{137-141}$ A new formulation of FK506 has been developed for the acute stroke indication, FK506 Lipid Complex-Gilead (FK506 LCG). Preliminary studies demonstrated a dose-dependent hypothermia and increase in blood pressure in animals, and a transient increase in blood pressure and heart rate in humans. Overall, this compound was well tolerated and a randomized, double-blind, placebo-controlled dose-escalation study is planned to determine the safety, tolerability, and pharmacokinetics of FK506 LCG in stroke patients. Criteria for enrollment include ischemic stroke within $12 \mathrm{~h}$ of onset, and moderate-to-severe deficit with clinical evidence of cortical involvement.

Corticosteroids theoretically may interrupt the inflammatory cascade that occurs during stroke. Recent experimental data posits that corticosteroids activate endothelial NO synthase activity via a non-transcriptional pathway, thereby augmenting regional cerebral blood flow and reducing infarct volume. ${ }^{142}$ Although corticosteroids substantially reduce stroke size in experimental models, trials using various routes of administration, dosage, and duration of treatment with dexamethasone have failed to demonstrate a beneficial effect of steroids. ${ }^{143,144}$ Steroids do, however, increase infectious and hyperglycemic complication rates. A systematic review of published randomized trials comparing steroids to placebo within $48 \mathrm{~h}$ of onset concluded that there is insufficient evidence to justify corticosteroid use after ischemic stroke. ${ }^{145}$ In this review, data from 453 patients within seven trials revealed that treatment did not reduce mortality or improve outcome. The substantial time delay to drug administration is a possible culprit for negative results. Additionally, the detrimental side effects of corticosteroid may be mediated by the transcriptional genomic activities of steroids, thereby limiting their clinical utility. Therefore, novel compounds that selectively activate non-transcriptional glucocorticoid receptor activity may provide neuroprotection without the deleterious effects. ${ }^{146}$ Such compounds are under development.

Human serum albumin is a multifunctional protein with neuroprotective properties in experimental models of focal ischemia even when administered up to $4 \mathrm{~h}$ after induction of reversible ischemia. ${ }^{147}$ Several mechanisms have been speculated for its neuroprotective capacity, including inhibition of lipid peroxidation (antioxidant), maintenance of microvascular integrity, inhibition of endothelial cell apoptosis, ${ }^{148}$ hemodilution, and mobilization of free fatty acids required for restoration of damaged neurons. ${ }^{149}$ Although non-albumin hemodilution trials have failed to demonstrate benefit, these were designed to test efficacy of hemodilution, not cytoprotection per se. A pilot study of albumin is underway.

\section{Membrane "stabilizers" and trophic factors}

The monosialoganglioside GM-1 is thought to limit excitotoxicity and facilitate nerve repair and regrowth. In a study of 792 acute stroke patients, there was a nonsignificant trend toward greater recovery in patients treated for 3 weeks with GM-1 compared to placebo. ${ }^{150}$ Post hoc analysis showed a statistically significant difference in neurologic outcome favoring GM-1 in the subgroup of patients treated within $4 \mathrm{~h}$. There was no difference in mortality, and the drug had no significant side effects. To our knowledge, no further studies of gangliosides in acute stroke are planned.

Cerebrolysin is a compound consisting of free amino acids and biologically active small peptides that are products of the enzymatic breakdown of lipid free brain products. Experimental models have demonstrated neuroprotection although the mechanism of action is unclear. ${ }^{151}$ Several European small trials have suggested that cerebrolysin administered as a continuous infusion for 20 days improves motor function and global function compared to placebo. ${ }^{152}$ Larger clinical trials would be required to confirm neuroprotection and determine pharmacokinetics/dynamics of this peptide.

Energy failure and activation of phospholipases during ischemia lead to breakdown of cellular membranes and ultimately to neuronal death. Cytidine- 5 '-diphosphocho- 
line (citicoline) is the rate-limiting intermediate in the biosynthesis of phosphatidylcholine that is incorporated into the membrane of injured neurons and may prevent membrane breakdown into free-radical-generating lipid byproducts. Citicoline has exhibited a neuroprotective effect in a variety of CNS injury models, including focal ischemia. ${ }^{153}$ However, the neuroprotective capacity is modest, and is lost if the onset of treatment is delayed by $3 \mathrm{~h} .{ }^{154}$ Despite the extensive work performed with experimental models, the exact mechanism of action remains elusive. However, it is believed to be due to increased phosphatidylcholine synthesis and inhibition of phospholipase A2 within the injured brain. During ischemia, choline supply is limited and membrane phospholipids are hydrolyzed to provide a source of choline for neurotransmitter synthesis. This autocannibalism ultimately leads to death of cholinergic neurons. Additionally, recent evidence shows that citicoline reduces expression of pro-caspases and other proteins involved in apoptotic cell death after focal ischemia. ${ }^{155}$

A randomized dose-response trial in 259 patients found a significant difference in functional outcome (BI and $\mathrm{mRS}$ ), neurologic function (NIHSS score), and cognitive function (MMSE) favoring oral citicoline. ${ }^{156}$ Both 500 and $2000 \mathrm{mg}$ citicoline had a significant effect on favorable outcome at 3-month outcome (BI) after adjustment for initial stroke severity. There were no doserelated serious adverse events or deaths with the exception of mild dizziness experienced at $2000 \mathrm{mg}$ /day. A subsequent phase 3 U.S. trial randomized 394 acute ischemic stroke patients within $24 \mathrm{~h}$ of onset to placebo or citicoline (500 mg orally daily) for 6 weeks. Patients with moderate-to-severe strokes within the middle cerebral artery territory were included. ${ }^{157}$ An imbalance of stroke severity occurred with significantly more patients with NIHSS $<8$ randomized to the placebo group. There was no statistical difference in planned secondary analyses and the primary efficacy analysis was rendered unreliable due to non-proportional distribution of patients. Post hoc analyses revealed that in the subgroup of patients with baseline NIHSS $>7$, citicoline-treated patients were significantly more likely to achieve a full recovery (placebo $21 \%$, citicoline $33 \%, p=0.05$ ).

Based in part on this subgroup analysis, another large phase 3 trial was conducted to evaluate the efficacy of higher dose citicoline (2000 $\mathrm{mg} /$ day $)$ administered within $24 \mathrm{~h}$ of onset to patients with baseline NIHSS $>7 .{ }^{158}$ There was no difference between citicoline and placebo-treated patients in the planned primary outcome defined as improvement from baseline NIHSS score $\geq 7$ points. However, post hoc analyses found a significant positive effect of treatment on recovery and a global test of multiple outcomes. The neutral results of this trial may have been due to the chosen primary endpoint that may not be reflective of recovery.
An important trial evaluating the effect of citicoline on MRI lesion volume demonstrated the potential utility of neuroimaging as a surrogate marker of neuroprotective efficacy. ${ }^{159}$ One hundred patients with baseline NIHSS score $>4$ presenting with a diffusion-weighted abnormality within $24 \mathrm{~h}$ of stroke onset were randomized to placebo or citicoline $500 \mathrm{mg} /$ day for 6 weeks. At 12 weeks, the ischemic lesion volume expanded by $180 \%$ in placebo patients compared with $34 \%$ among citicolinetreated patients. A significant association was found between reduction of lesion volume and improvement of NIHSS by 7 points or more. This relationship between clinical outcome and lesion volume supports the use of diffusion-weighted image as a surrogate marker of neuroprotective efficacy.

Finally, intravenous citicoline of various doses and treatment duration has been evaluated in several nonU.S. trials with significant improvements in recovery demonstrated by all trials. A small pilot study comparing the efficacy of citicoline $(1,000 \mathrm{mg} /$ day for 30 days $)$ to placebo found that $71 \%$ of citicoline-treated patients improved from baseline compared with only $31 \%$ of placebo-treated patients. ${ }^{160}$ The largest trial included 272 patients randomized to citicoline or placebo. In this trial a $26 \%$ relative difference on a global improvement rating scale favoring citicoline treatment over placebo was demonstrated. ${ }^{161}$

A recent meta-analysis of 7 controlled clinical stroke trials showed that citicoline treatment was associated with significant reductions in rates of long-term death or disability. ${ }^{162}$ A more recent pooled analysis of oral citicoline clinical trials in acute ischemic stroke sought to determine the effects of citicoline on neurologic recovery. ${ }^{163}$ A systematic search identified all prospective, randomized, placebo-controlled, double-blind clinical trials of citicoline in patients with moderate-to-severe strokes (NIHSS score $\geq 8$ ) and good pre-stroke functioning (mRS $<2)$. Of 1,652 total patients, 1,372 fulfilled the inclusion criteria. Three-month recovery (composite NIHSS $\leq 1, \mathrm{mRS} \leq 1, \mathrm{BI} \geq 95$ ) was achieved in $25.2 \%$ citicoline-treated patients compared with $20.2 \%$ placebotreated patients (Table 6). The largest difference in recovery was seen in patients treated with the highest dose (2000 mg) of citicoline. The promising results of these large-scale analyses will likely prompt further citicoline studies since this is the first time that meta-analysis of cytoprotective trials has yielded positive results.

Finally, combination of citicoline and intravenous thrombolysis has been shown to significantly reduce infarct volume compared with either treatment alone in a rat embolic stroke model; however, this treatment combination has not yet been tested in humans. ${ }^{164}$ Given the positive results of the recent meta-analyses, evaluation of combined citicoline and TPA appears to be the logical next step. 
TABLE 6. Meta-Analyses of Citicoline Studies Intent-to-Treat Set: GEE Estimated Probabilities of Global Recovery after 12 Weeks of Follow-Up ${ }^{163}$

\begin{tabular}{|c|c|c|c|c|c|}
\hline & \multicolumn{5}{|c|}{ Global Recovery at Week 12} \\
\hline & Citicoline \% & Placebo \% & OR & $95 \% \mathrm{CI}$ & $p$ \\
\hline Citicoline vs. placebo (4 trials, 1372 patients) & 25.2 & 20.2 & 1.33 & $1.10-1.62$ & 0.0034 \\
\hline \multicolumn{6}{|l|}{$\begin{array}{l}\text { Doses } \\
\text { Citicoline } 500 \mathrm{mg} v_{S, \text { placebo }}\end{array}$} \\
\hline Study $001 \mathrm{a}^{6}$ & 27.7 & 11.4 & 2.98 & $1.25-7.02$ & 0.0129 \\
\hline Study $007^{7}$ & 24.2 & 16.6 & 1.61 & $0.93-2.78$ & 0.0890 \\
\hline Study $010^{8}$ & 17.1 & 24.0 & 0.65 & $0.28-1.48$ & 0.3078 \\
\hline Overall & 20.8 & 15.7 & 1.42 & $0.96-2.093$ & 0.0782 \\
\hline \multicolumn{6}{|l|}{ Citicoline $1000 \mathrm{mg} v s$. placebo } \\
\hline Study $001 \mathrm{a}^{6}$ & 9.1 & 10.7 & 0.84 & $0.35-2.15$ & 0.7096 \\
\hline \multicolumn{6}{|l|}{ Citicoline $2000 \mathrm{mg} v \mathrm{~s}$. placebo } \\
\hline Study $001 \mathrm{a}^{6}$ & 25.19 & 9.8 & 3.098 & $1.18-8.12$ & 0.0214 \\
\hline Study $018^{9}$ & 28.47 & 23.25 & 1.314 & $1.0-1.65$ & 0.0183 \\
\hline Overall & 27.9 & 21.9 & 1.38 & $1.10-1.72$ & 0.0043 \\
\hline
\end{tabular}

OR $=$ odds ratio. From Daralos et al. Oral citicoline in acute stroke: an individual patient data pooling analysis of clinical trials. Stroke 33:2850-2857. Copyright (c) 2002, Lippincott Williams and Wilkins. All rights reserved.

Erythropoietin (EPO) is a mediator of the physiological response to hypoxia via activation of the EPO receptor, a member of the cytokine-receptor superfamily. The overall result of EPO receptor activation is cell proliferation, inhibition of apoptosis, and erythroblast differentiation. ${ }^{165}$ EPO may also provide antioxidant activity and resistance to glutamate toxicity. ${ }^{166-168}$ A focal ischemia model demonstrated that intraperitoneal epoetin alpha administered $6 \mathrm{~h}$ after ischemia provided 50\% protection and this protection occurs via an anti-apoptotic mechanism. ${ }^{169}$ An initial safety study revealed that intravenously administered EPO is safe and able to enter the brain in stroke patients. Currently a clinical trial is underway to test the efficacy of recombinant human EPO in acute stroke.

Trophic factors are emerging as potential cytoprotective agents, although their role may be more important in the recovery phase. Basic fibroblast growth factor (bFGF, Fiblast) is a polypeptide that is trophic for brain neurons, glia, and endothelial cells and may prevent down-regulation of anti-apoptotic proteins such as Bcl2. ${ }^{170}$ Animal studies have shown that bFGF is effective in reducing infarct volume in acute ischemia models, as well as promoting synaptogenesis and functional recovery. ${ }^{171,172}$ Additionally, synergistic protective effects have been observed with the combination of bFGF with either citicoline or caspase inhibitors. ${ }^{173,174}$

A double-blind, placebo-controlled clinical trial evaluated two doses of bFGF (5 mg or $10 \mathrm{mg}$ ) compared to placebo. ${ }^{175}$ Patients with acute, moderate-to-severe stroke (NIHSS $>6$ ) were randomized within $6 \mathrm{~h}$ of onset to a single 24-h infusion of bFGF or placebo. An interim efficacy analysis predicted only a nominal chance of significant benefit and the trial was terminated after enrolling 286 of 900 planned patients. A non-significant trend for favorable outcome was seen in the low-dose group, whereas a non-significant disadvantage was seen in the high-dose group. Post hoc analysis further suggested efficacy of the low-dose regimen. Dose-dependent adverse events included leukocytosis and relative hypotension. An unpublished, multicenter controlled phase $2 / 3$ trial was halted after interim analysis revealed significant increased mortality in patients treated with bFGF.

The poor BBB penetration of bFGF necessitated high systemic doses and peripheral side effects may offset the therapeutic effect. Recently, conjugation of bFGF to a BBB drug-delivery vector (OX26-SA) has demonstrated neuroprotection at a lower, systemically administered dosage in a rodent model. ${ }^{176}$

Other trophic factors such as platelet-derived growth factor, insulin-derived growth factor, and glial cell linederived neurotrophic factor have also shown promise in animal stroke models, possibly through angiogenic mechanisms. ${ }^{177-179}$ These have not been studied in humans.

Many of the novel neuroprotectants, especially trophic factors and anti-inflammatory agents, exist as peptides unable to cross the BBB. Animal models have demonstrated enhanced delivery and neuroprotection when protein agents are conjugated to a delivery vector. Such enhanced delivery mechanisms include reformulation of the neurotherapeutic protein by conjugation and biotinylation, or creation of a fusion protein linked to transduction domains. Enhanced drug delivery systems have several benefits. First, obviously this may enable delivery of neurotherapeutic agents that otherwise do not have access to the brain. Secondly, neuroprotection may be achieved at lower systemic doses thereby allowing administration of agents previously exhibiting dose-limiting side effects. Lastly, conjugation to BBB delivery 


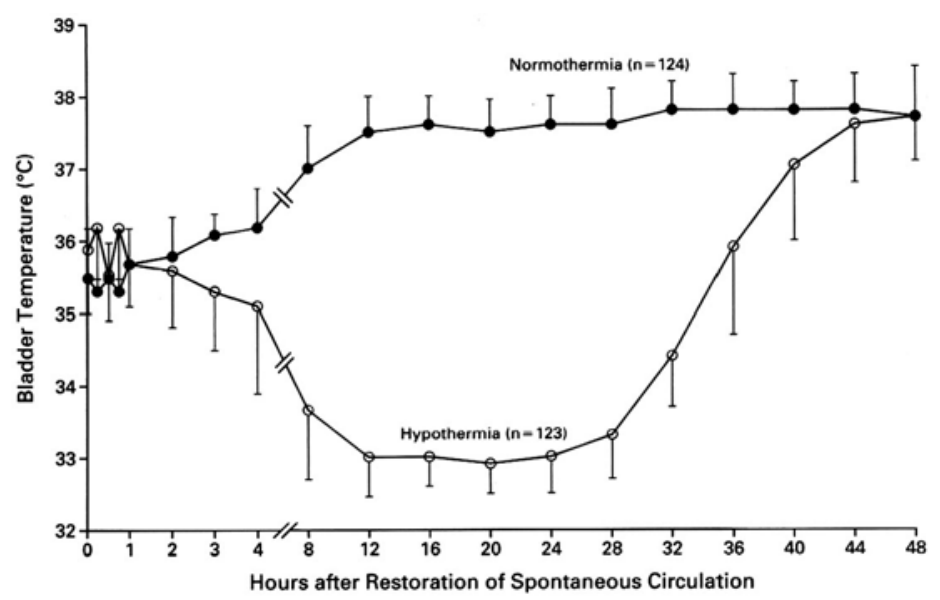

FIG. 4. Time course of bladder temperature in normothermia and hypothermia patient groups. From the Hypothermia After Cardiac Arrest Study Group. Mild therapeutic hypothermia to improve the neurologic outcome after cardiac arrest. N Engl J Med 346:557-563. Copyright @ 2002, Massachusetts Medical Society. All rights reserved.

vectors may decrease distribution to peripheral organs. Experimental models have already demonstrated these benefits. Bcl-XL, an anti-apoptotic peptide member of the Bcl-2 protooncogene family, was successfully fused to the HIV TAT protein, penetrated the BBB after systemic administration and imparted neuroprotection. ${ }^{180}$

\section{Hypothermia}

The neuroprotective action of mild-to-moderate $\left(29^{\circ} \mathrm{C}\right.$ to $35^{\circ} \mathrm{C}$ ) systemic hypothermia has been demonstrated in numerous animal models of global and focal cerebral ischemia. ${ }^{181-190}$ There are many hypothesized mechanisms for this protection, including restoration of neurotransmitter balance, ${ }^{191,192}$ reduction in cerebral metabolism, ${ }^{193}$ preservation of the BBB, inhibition of apoptosis, ${ }^{194}$ and attenuation of inflammatory response. ${ }^{195,196}$ Perhaps the consistent and robust benefit of hypothermia across multiple laboratories and animal models is because it works through multiple pathways, all conspiring to have a greater effect than more precisely targeted therapies. Several general principles have emerged from the extensive work investigating the cerebro-protective effects of hypothermia.

First, hypothermia applied during the ischemic period (intra-ischemic) is more protective than hypothermia af- ter reperfusion (post-ischemic). The efficacy of postischemic hypothermia is dependent upon the interval between onset of ischemia and induction of hypothermia, achievement of target temperature, and duration of treatment. Lastly, hypothermia is more efficacious for global ischemia/reperfusion than for focal ischemia, and for transient focal ischemia than for permanent focal ischemia, suggesting that hypothermia may be most beneficial when coupled to thrombolysis/recanalization.

Hypothermia after cardiac arrest has been investigated with use of surface cooling techniques. ${ }^{197,198}$ Recently, two large trials have been published conclusively establishing the neuroprotective effects and safety of hypothermia after cardiac arrest. ${ }^{199,200}$ These studies are the first proof of principle that neuroprotection can be realized in humans. The median time to achieve target temperature from return of spontaneous circulation was $8 \mathrm{~h}$ with surface cooling (FIG. 4). Neurologic outcome was significantly improved in patients treated with hypothermia compared with controls in both trials (Table 7 and Table 8). The efficacy demonstrated, despite relatively long delay times to achieving target temperature, is consistent with animal studies after global forebrain isch-

TABLE 7. Outcome with Hypothermia Treatment after Cardiac Arrest

\begin{tabular}{lcccc}
\hline Outcome & Normothermia & Hypothermia & $\begin{array}{c}\text { Risk Ratio (95\% CI) } \\
\text { no./total no. (\%) }\end{array}$ & $p$ Value $^{\dagger}$ \\
\hline Favorable neurologic outcome & $54 / 137(39)$ & $75 / 136(55)$ & $1.40(1.081 .81)$ & 0.009 \\
Death & $76 / 138(55)$ & $56 / 137(41)$ & $0.74(0.580 .95)$ & 0.02 \\
\hline
\end{tabular}

\footnotetext{
* The risk ratio was calculated as the rate of a favorable neurologic outcome or the rate of death in the hypothermia group divided by the rate in the normothermia group

†Two-sided $p$ values are based on Pearson's chi-square tests.

${ }^{\ddagger}$ A favorable neurologic outcome was defined as a cerebral performance category of 1 (good recovery) or 2 (moderate disability). One patient in the normothermia group and one in the hypothermia group were lost to neurologic follow-up.

$\mathrm{CI}=$ confidence interval.

From the Hypothermia After Cardiac Arrest Study Group. Mild therapeutic hypothermia to improve the neurologic outcome after cardiac arrest. N Engl J Med 346:557-563. Copyright (c) 2002, Massachusetts Medical Society. All rights reserved.
} 
TABLE 8. Outcome with Hypothermia Treatment after Cardiac Arrest

Outcome*

Normal or minimal disability (able to care for self, discharged directly to home)

Moderate disability (discharged to a rehabilitation facility)

Severe disability, awake but completely dependent (discharged to a long-term nursing facility)

Severe disability, unconscious (discharged to a long-term nursing facility)

Death

$$
\text { Hypothermia }(n=43) \quad \text { Normothermia }(n=34)
$$

Number of Patients

$\begin{array}{ll}15 & 7 \\ 6 & 2 \\ 0 & 1 \\ 0 & 1 \\ 22 & 23\end{array}$

\begin{abstract}
* The difference between the rates of a good outcome (normal or with minimal or moderate disability) in the hypothermia and the normothermia groups ( $49 \%$ and $26 \%$, respectively) was 23 percentage points (95\% confidence interval, 13 to 43 percentage points: $p=$ 0.046). The unadjusted odds ratio for a good outcome in the hypothermia group as compared with the normothermia group was 2.65 (95\% confidence interval, 1.02 to $6.88 ; p=0.046$ ). The odds ratio for a good outcome in the hypothermia group as compared with the normothermia group, after adjustment by logistic regression for age and time from collapse to return of spontaneous circulation, was 5.25 ( $95 \%$ confidence interval, 1.47 to 18.76; $p=0.011$ ). From Bernard et al. Treatment of comatose survivors of out-of-hospital cardiac arrest with induced hypothermia. J Engl J Med 346:557-563. Copyright ( 2002 , Massachusetts Medical Society. All rights reserved.
\end{abstract}

emia, showing that such delayed therapy can be beneficial if it is prolonged for 12 to $24 \mathrm{~h}^{201}$

Observations have been made that hyperthermia independently predicts poor outcome in stroke patients, whereas lower body temperature at presentation is associated with improved survival and clinical outcome. ${ }^{202-}$ 205 Several studies have also looked at the safety and feasibility of hypothermia in ischemic stroke patients. ${ }^{206-211}$ However, the majority of these studies have focused on salvage hypothermic management of elevated intracranial pressure in patients with malignant middle cerebral artery territory infarcts, rather than as a standalone neuroprotective modality. These early studies have used surface cooling methods to achieve significant depths of hypothermia requiring sedation/neuromuscular blockade for patient tolerance of cooling.

In a pilot study, Kreiger et $\mathrm{al}^{210}$ used surface cooling to achieve post-ischemic hypothermia to $32^{\circ} \mathrm{C}$ in 10 ventilated and sedated patients. All patients had severe middle cerebral artery (MCA) infarcts, and the majority were treated with either intravenous or intra-arterial TPA before hypothermia. Hypothermia was initiated $6.2 \pm 1.3 \mathrm{~h}$ after stroke onset, with achievement of maximal hypothermia at $3.5 \pm 1.5 \mathrm{~h}$ after initiation of cooling. The duration of hypothermia (mean $22.8 \pm 8 \mathrm{~h}$ ) was determined by reestablishment of cerebral perfusion as determined by serial transcranial Doppler examinations. This study showed that post-ischemic hypothermia is safe and feasible after administration of TPA in stroke patients.

Kammersgaard et $\mathrm{al}^{207}$ published a case-control study illustrating the feasibility of moderate hypothermia in awake patients within $12 \mathrm{~h}$ of stroke onset. Hypothermia was initiated upon admission with surface cooling to achieve $35.5^{\circ} \mathrm{C}$ and was maintained for $6 \mathrm{~h}$. Pethidine (meperidine) was effectively used to reduce shivering in all patients. This data supports the feasibility of using mild hypothermia to treat awake stroke patients without the inherent risks of intubation, sedation, and paralytics.

Translating the neuroprotection established with early hypothermia in preclinical intra-ischemic and early postischemic models to human stroke patients has been one of the most difficult obstacles thus far. Hypothermia must be rapidly initiated and stably maintained. Endovascular cooling via specialized intravenous catheters may be a more efficient means of inducing and maintaining hypothermia, and possibly enhancing the efficacy of neuroprotection. Georgiadis et $\mathrm{al}^{211}$ evaluated the feasibility and safety of catheter-induced cooling in acute stroke patients. The rate of cooling was $1.4 \pm 0.6^{\circ} \mathrm{C} / \mathrm{h}$, which is faster than the majority of surface cooling techniques. Two of the patients in this study were treated with i.v. TPA; however, the delay between TPA and catheter insertion/hypothermia induction did not permit adequate evaluation of safety.

Ongoing safety and feasibility trials are being conducted with catheter-induced hypothermia in both cardiac arrest and stroke patients. One current trial is investigating 12 and $24 \mathrm{~h}$ of catheter-induced hypothermia $\left(33^{\circ} \mathrm{C}\right)$ within $12 \mathrm{~h}$ of stroke onset in awake patients, some treated with i.v. TPA. This current work is being performed in awake patients using pharmacologic reduction of the shivering threshold with buspirone and meperidine. Such shivering protocols obviate the need to intubate, sedate, and paralyze patients, which prevents adequate monitoring of neurologic status and predisposes to infectious and cardiovascular adverse events.

\section{Caffeinol}

A novel combination of the combination of caffeine and ethanol (caffeinol) has demonstrated more robust neuroprotection than many other experimental and clinically relevant agents tested in the laboratory. ${ }^{212}$ When 
used individually, caffeine had no effect and ethanol actually increased infarct volume. However, animal studies have demonstrated a significant $83 \%$ reduction in infarct volume with the acute administration of the combination of caffeine $10 \mathrm{mg} / \mathrm{kg}$ and $5 \%$ ethanol 0.325 $\mathrm{gm} / \mathrm{kg}$ given intravenously over $120 \mathrm{~min}$ in rats subjected to experimental focal cerebral ischemia. Significant benefit was seen with treatment delayed up to $3 \mathrm{~h}$ post-stroke. Extensive work has shown that combining i.v. TPA with caffeinol imparts no increased risk of intracranial hemorrhage in vivo, and no reduction of TPA fibrinolytic activity in vitro. ${ }^{213}$

The protective effect of caffeinol has recently been confirmed in the suture model of transient MCA occlusion, with the predominant effect on cortical salvage. The protective mechanism is likely due to the synergistic effect of caffeine and ethanol on the excitatory/inhibitory balance between neurotransmitter systems. Adenosine and NMDA receptor antagonism and GABA enhancement are hypothesized to be mechanistically involved in this neurochemical.

An open-label, dose-escalation evaluation of caffeine and ethanol in acute ischemic stroke patients within $6 \mathrm{~h}$ of symptom onset has been completed. ${ }^{214}$ Twenty-three patients with suspected cortical infarct with NIHSS score $>4$ were treated at doses ranging from 6 to $8 \mathrm{mg} / \mathrm{kg}$ of caffeine and 0.2 to $0.4 \mathrm{gm} / \mathrm{kg}$ of ethanol over $2 \mathrm{~h}$ to determine the optimal dose. Concomitant thrombolytic therapy was given in 8 patients. A dose has been identified that results in plasma levels that produce optimal therapeutic effect in animals (caffeine 5 to $10 \mu \mathrm{g} / \mathrm{ml}$ and ethanol 30 to $50 \mathrm{mg} / \mathrm{dl}$ ) and that are clinically well-tolerated by patients without any significant adverse effects.

Combining caffeinol with hypothermia to $35^{\circ} \mathrm{C}$ increased the amount of neuroprotection in a focal ischemia model compared to either caffeinol or hypothermia alone. ${ }^{213}$ In this model, hypothermia was started $60 \mathrm{~min}$ after the onset of ischemia and continued for $240 \mathrm{~min}$. A pilot study designed to establish the feasibility and safety of administering both caffeinol and mild systemic hypothermia in acute ischemic stroke patients treated with i.v. TPA, within $5 \mathrm{~h}$ of symptom onset (caffeinol within $4 \mathrm{~h}$ and hypothermia within $5 \mathrm{~h}$ ) is just starting. The dosing schedule $(8 \mathrm{mg} / \mathrm{kg}$ and $0.4 \mathrm{gm} / \mathrm{kg} 10 \%$ ethanol) identified in the caffeinol dose-escalation trial will serve as the template.

\section{Blood substitutes and oxygen delivery}

Compounds derived from human hemoglobin have a dual property: they may be neuroprotective by improving tissue oxygenation, and they may also augment perfusion because of their low viscosity. Several cell-free hemoglobin solutions are under clinical evaluation, but development has been cautious because of concerns about potential allergic and infectious complications, and nephrotoxicity. The agent that went farthest along in clinical development is diaspirin cross-linked hemoglobin (DCLHb), which is human hemoglobin derived from banked red blood cells, heat-treated, and diaspirin crosslinked to prevent dissociation. It has similar oxygen affinity to that of blood. Probably because hemoglobin binds endothelial NO, it has a slight pressor effect. Studies in animal stroke models have consistently shown improved perfusion of ischemic regions and reduced infarct size. ${ }^{215-218}$ In one study, DCLHb was able to double the length of time MCA occlusion could be withstood before ischemic damage appeared. ${ }^{218}$

A multicenter, single-blind phase 2 safety/dose-finding trial randomized 85 patients to DCLHb or saline. ${ }^{219} \mathrm{~Pa}$ tients with acute ischemic stroke in the anterior circulation, within $18 \mathrm{~h}$ of onset of symptoms were enrolled. Three DCLHb dosing regimens were evaluated, each involving 12 doses over $72 \mathrm{~h}$. DCLHb caused a rapid rise in mean arterial blood pressure. The pressor effect was not accompanied by complications or excessive need for antihypertensive treatment. Multivariate logistic regression analysis showed that a severe stroke at baseline and treatment with DCLHb were independent predictors of worse outcome (mRS 3-6) at 3 months. More serious adverse events and deaths occurred in DCLHb-treated patients than in control patients.

Normobaric hyperoxia confers cortical protection when administered within $30 \mathrm{~min}$ of ischemia in rodents. ${ }^{220}$ Normobaric therapy is practically easier to deliver than hyperbaric therapy. Based on its simplicity, low cost and safety, normobaric hyperoxia may be initiated by first responders in the field and clinical trials are anticipated.

Hyperbaric oxygen (HBO) treatment presumably increases oxygen delivery to the ischemic penumbra, thereby prolonging the functional activity of this potentially salvageable tissue. Mechanistically, administration of $100 \%$ oxygen at greater than atmospheric ambient pressure increases the amount of oxygen physically dissolved in blood. Other postulated protective actions include inhibition of neutrophil sequestration ${ }^{221}$ and reduction of peri-infarct glucose, glutamate, and pyruvate levels. ${ }^{222}$ Although the majority of animal models demonstrate a beneficial effect of HBO on outcome and infarct volume, ${ }^{223-227}$ others do not, ${ }^{228-230}$ and controversy prevails regarding the neuroprotective potential of HBO therapy in both clinical and experimental focal ischemia. Increased free radical generation and lipid peroxidation is a theoretical risk of HBO that may counteract neuroprotective mechanisms of action. A study of $\mathrm{HBO}$ at three atmospheres in a rodent model of focal ischemia demonstrated neuroprotection without alteration of lipid peroxidation.

Human experience with ischemic stroke and HBO treatment yields similar conflicting results. ${ }^{231,232}$ A double-blind pilot study evaluated the safety and efficacy of HBO ther- 
apy compared to hyperbaric air (HBA) in patients within $24 \mathrm{~h}$ of ischemic stroke onset. A total of 34 patients were exposed to $40 \mathrm{~min}$ of hyperbaric treatment (17 HBO, 17 HBA) at 1.5 atmospheres for 10 dives total. The mean Orgogozo neurological assessment score at 1 year was significantly better with the HBO therapy than HBA; however, no statistical difference was found in the mRS scores or net difference between pre- and post-treatment scores. This study concluded that HBO treatment was safe and possibly efficacious. A larger trial is recruiting patients.

\section{Conclusion}

In summary, encouraging signals have recently been detected in human studies of hypothermia after cardiac arrest and citicoline for ischemic stroke, suggesting that clinically meaningful cytoprotection after stroke may still be achievable despite 10 years of largely failed trials. An ongoing large trial of magnesium is nearing completion. If this trial is negative, it should determine once and for all that delayed treatment with drugs targeting single "upstream" events will not succeed. Phase 1 and 2 trials that are now being designed reflect the lessons learned from earlier failed trials. These include ultra-early treatment (FAST-MAG), targeting "downstream" events (FK506, NXY-059, trophic factors, EPO, albumin) that may be more amenable to post-ischemic treatment, or combining agents that together have high potency by targeting multiple pathways (caffeinol/hypothermia). Hopefully, one or more of these approaches, or some even more effective approach to cytoprotection will prove effective. However, careful and thorough preclinical testing showing robust benefit in multiple labs and models with clinically realistic treatment delay, and carefully conducted phase 1 and 2 trials showing that neuroprotective doses can be achieved in stroke patients without unacceptable toxicity, should be required before committing valuable resources to more large phase 3 studies.

Acknowledgments: L. Labiche was supported by NINDS Training Grant number T32NS07412.

\section{REFERENCES}

1. Bean BP. Nitrendipine block of cardiac calcium channels: highaffinity binding to the inactivated state. Proc Natl Acad Sci USA 81:6388-6392, 1984

2. Grotta JC. Clinical aspects of the use of calcium antagonists in cerebrovascular disease. Clin Neuropharmacol 14:373-390, 1991.

3. Petruk KC, West M, Mohr G, Weir BK, Benoit BG, Gentili F et al. Nimodipine treatment in poor-grade aneurysm patients: results of a multicenter double-blind placebo-controlled trial. J Neurosurg 68:505-517, 1988.

4. Pickard JD, Murray GD, Illingworth R, Shaw MD, Teasdale GM, Foy PM et al. Effect of oral nimodipine on cerebral infarction and outcome after subarachnoid haemorrhage: British aneurysm nimodipine trial. BMJ 298:636-642, 1989.

5. Ohman J, Servo A, Heiskanen O. Long-term effects of nimodipine on cerebral infarcts and outcome after aneurysmal subarachnoid hemorrhage and surgery. J Neurosurg 74:8-13, 1991
6. Barker FG, Ogilvy CS. Efficacy of prophylactic nimodipine for delayed ischemic deficit after subarachnoid hemorrhage: a metaanalysis. J Neurosurg 84:405-414, 1996.

7. Feigin VL, Rinkel GJ, Algra A, Vermeulen M, van Gijn J. Calcium antagonists for aneurismal subarachnoid haemorrhage. $\mathrm{Co}$ chrane Database Syst Rev CD000277, 2000.

8. Gelmers HJ. The effects of nimodipine on the clinical course of patients with acute ischemic stroke. Acta Neurol Scand 69:232239, 1984.

9. Paci A, Ottaviano P, Trenta A, Iannone G, DeSantis L, Lancia G et al. Nimodipine in acute ischemic stroke: a double-blind controlled study. Acta Neurol Scand 80:282-286, 1989.

10. Gelmers HJ, Hennerici M. Effect of nimodipine on acute ischemic stroke: Pooled results from 5 randomized trials. Stroke 21[Suppl 12]:IV81-IV84, 1990.

11. Nag D, Garg RK, Varma M. A randomized double-blind controlled study of nimodipine in acute cerebral ischemic stroke. Indian J Physiol (Lond) Pharmacol 42:555-558, 1998.

12. The American Nimodipine Study Group. Clinical trial of nimodipine in acute ischemic stroke. Stroke 23:3-8, 1992.

13. Wahlgren NG, MacMahon DG, De Keyser J, Ryman T, INWEST Study Group: Intravenous Nimodipine West European Stroke Trial (INWEST) of nimodipine in the treatment of acute ischemic stroke. Cerebrovasc Dis 4:204-210, 1994.

14. Kaste M, Fogelholm R, Erila T et al. A randomized, double-blind, placebo-controlled trial of nimodipine in acute ischemic hemispheric stroke. Stroke 25:1348-1353, 1994.

15. Ahmed N, Nasman P, Wahlgren NG. Effect of intravenous nimodipine on blood pressure and outcome after acute stroke. Stroke 31:1250-1255, 2000.

16. Mohr JP, Orgogozo JM, Harrison M, Hennerici M, Wahlgren NG, Gelmers JH et al. Meta-analysis of oral nimodipine trials in acute ischemic stroke. Cerebrovasc Dis 4:197-203, 1994.

17. Horn J, de Haan RJ, Verneulen M, Limburg M. Very Early Nimodipine Use in Stroke (VENUS): a randomized, doubleblind, placebo-controlled trial. Stroke 32:461-465, 2001.

18. Rosenbaum D, Zabramski J, Frey J, Yatsu F, Marler J, Spetzler R et al. Early treatment of ischemic stroke with a calcium antagonist. Stroke 22:437-441, 1991.

19. Koh JY, Cotman CW. Programmed cell death: its possible contribution to neurotoxicity mediated by calcium channel antagonists. Brain Res 587:233-240, 1992.

20. Grotta JC, Picone CM, Ostrow PT, Strong RA, Earls RM, Yao LP et al. CGS-19755, a competitive NMDA receptor antagonist, reduces calcium-calmodulin binding and improves outcome after global cerebral ischemia. Ann Neurol 27:612-619, 1990.

21. Simon R, Shiraishi K. N-methyl-D-aspartate antagonist reduces stroke size and regional glucose metabolism. Ann Neurol 27:606611, 1990.

22. Simmonds J, Sailer T, Moyer J. The effects of CGS-19755 in rat focal cerebral ischemia produced by tandem ipsilateral common carotid artery and middle cerebral artery occlusion [abstract]. Soc Neurosci Abstr 19:1647, 1993.

23. Grotta J, Clark W, Coull B, Pettigrew LC, Mackay B, Goldstein $\mathrm{KB}$ et al. Safety and tolerability of the glutamate antagonist CGS 1975 (selfotel) in patients with acute ischemic stroke: results of a phase IIa randomized trial. Stroke 26:602-605, 1995.

24. Davis SM, Lees KR, Albers GW, Diener HC, Markabi S, Karlsson G, Norris J. Selfotel in acute ischemic stroke: possible neurotoxic effects of an NMDA antagonist. Stroke 31:347-354, 2000 .

25. Steinberg GK, Perez-Pinzon MA, Maier CM et al. CGS-19755: correlation of in vitro neuroprotection, protection against experimental ischemia and CSF levels in cerebrovascular surgery patients. Abstract presented at Proceedings of the 5th International Symposium on Pharmacology of Cerebral Ischemia, Marburg, Germany, July 20-22, 1994.

26. Albers GW, Atkinson RP, Kelley RE, Rosenbaum DM. Safety, tolerability, and pharmacokinetics of the N-methyl-B-aspartate antagonist dextrorphan in patients with acute stroke. Stroke 26: 254-258, 1995.

27. Minematsu K, Fisher M, Li L, Davis MA, Knapp AG, Cotter RE et al. Effects of a novel MNDA antagonist on experimental stroke 
rapidly and quantitatively assessed by diffusion-weighted MRI. Neurology 43:397-403, 1993.

28. Dyker AG, Edwards KR, Fayad PB, Hormes JT, Lees KR. Safety and tolerability study of aptiganel hydrochloride in patients with an acute ischemic stroke. Stroke 30:2038-2042, 1999.

29. Albers GW, Goldstein LB, Hall D, for the Aptiganel Acute Stroke Investigators. Aptiganel hydrochloride in acute ischemic stroke: a randomized controlled trial. JAMA 21:2673-2682, 2001

30. Muir KW. Magnesium in stroke treatment. Postgrad Med J 78: 641-645, 2002.

31. Weglicki WB, Phillips TM. Pathobiology of magnesium deficiency: a cytokine/neurogenic inflammation hypothesis. $\mathrm{Am} \mathrm{J}$ Physiol (Lond) 263:R734-R737, 1992.

32. Yang Y, Li Q, Ahmad F, Shuaib A. Survival and histological evaluation of therapeutic window of post-ischemia treatment with magnesium sulfate in embolic stroke model of rat. Neurosci Lett 285:119-122, 2000.

33. Muir KW, Lees DR. A randomized, double-blind, placebo-controlled pilot trial of intravenous magnesium sulfate in acute stroke. Stroke 126:1183-1188, 1995.

34. Muir KW, Lees KR. Dose optimization of intravenous magnesium sulfate after acute stroke. Stroke 29:918-923, 1998.

35. Izumi Y, Roussl S, Pinard E, Seylaz J. Reduction of infarct volume by magnesium after middle cerebral artery occlusion in rates. J Cereb Blood Flow Metab 11:1025-1030, 1991.

36. Saver JL, Kidwell CS, Leary M et al. The field administration of stroke therapy-magnesium (FAST- MAG) pilot trial. Abstract presented at the ongoing clinical trials session, 26th International Stroke Conference, Fort Lauderdale, FL, Feb 2001.

37. Olney JW, Labruyere J, Price MT. Pathological changes induced in cerebrocortical neurons by phencyclidine and related drugs. Science 244:1360-1362, 1989.

38. Olney JW, Wozniak DF, Jevtovic-Todorovic V, Farber NB, Bittigau P, Ikonomidou C. Drug-induced apoptotic neurodegeneration in the developing brain. Brain Pathol 12:488-498, 2002

39. Lees KR. Cerestat and other NMDA antagonists in ischemic stroke. Neurology 49[Suppl 4]:S66-S69, 1997.

40. Bordi F, Pietra C, Ziviani L, Reggiani A. The glycine antagonist GV150526 protects somatosensory evoked potentials and reduces the infarct area in the MCAO model of focal ischemia in the rat. Exp Neurol 145:425-433, 1997.

41. Dyker AG. Lees KR. Safety and tolerability of GV150526 (a glycine site antagonist at the N-methyl-D-aspartate receptor) in patients with acute stroke. Stroke 30:986-992, 1999.

42. Sacco RL, DeRosa JT, Haley EC, Levin B, Ordronneau P, Phillips $\mathrm{SJ}$ et al., for the GAIN Americas Investigators. Glycine antagonist in neuroprotection for patients with acute stroke: GAIN Americas: a randomized controlled trial. JAMA 285:1719-1728, 2001.

43. Lees KR, Asplund K, Carolei A, Davis SM, Diener HC, Kaste $\mathrm{HM}$ et al, for the GAIN International Investigators. Glycine antagonist (gavestinel) in neuroprotection (GAIN International) in patients with acute stroke: A randomized controlled trial. Lancet 355:1949-1954, 2000.

44. Kawasaki-Yatsugi S, Ichiki C, Yatsugi S, Takahashi M, ShimizuSasamata M, Yamaguchi $\mathrm{T}$ et al: Neuroprotective effects of an AMPA receptor antagonist YM872 in a rat transient middle cerebral artery occlusion model. Neuropharmacology 39:211-217, 2000.

45. Suzuki M, Sasamata M, Miyata K. Neuroprotective effects of YM872 coadministered with t-PA in a rat embolic stroke model. Brain Res 959:169-172, 2003.

46. Smith SE, Meldrum BS. Cerebroprotective effect of lamotrigine after focal ischemia in rats. Stroke 26:117-121, 1995.

47. Traystman RJ, Klaus JA, DeVries AC, Shaivitz AB, Hurn PD. Anticonvulsant lamotrigine administered on reperfusion fails to improve experimental stroke outcomes. Stroke 32:783-787, 2001.

48. Leach MJ, Swan JH, Eisenthal D, Dopson M, Nobbs M. BW619C89, a glutamate release inhibitor, protects against focal cerebral ischemic damage. Stroke 24:1063-1067, 1993

49. Kawaguchi K, Graham SH. Neuroprotective effects of the glutamate release inhibitor 619C89 in temporary middle cerebral artery occlusion. Brain Res 749:131-134, 1991.

50. Muir KW, Holzapfel L, Lees KR. Phase II clinical trial of si- patrigine (619C89) by continuous infusion in acute stroke. Cerebrovasc Dis 10:431-436, 2000.

51. Sipatrigine in Stroke (SIS). Stroke Center Clinical Trials Directory.http://www.strokecenter.org/trials/TrialDetail.asp?ref=276\& browse $=$ acute [updated 7/3/2002].

52. Fosphenytoin Phase 3. Stroke Center Clinical Trials Directory. http:// www.strokecenter.org/trials/TrialDetail.asp?ref $=218 \&$ browse $=$ acute [updated 8/3/2000].

53. Gribkoff VK, Starrett JE, Dworetzky SI. The pharmacology and molecular biology of large-conductance calcium-activated (BK) potassium channels. Adv Pharmacol 37:319-348, 1997.

54. Bozik M, Hommel M, Grotta J et al. Efficacy and safety of MaxiPost in patients with acute stroke [abstract]. JNS 187:S252, 2001.

55. DeRyck M, Keersmaekers R, Clincke G, Janssen M, VanReet S. Lubeluzole, a novel benzothiazole, protects neurologic function after cerebral thrombotic stroke in rats: an apparent stereospecific effect [abstract]. Soc Neurosci Abstr 20:185, 1994.

56. Aronowski J, Strong R, Grotta JC. Treatment of experimental focal ischemia in rats with lubeluzole. Neuropharmacology 35: 689-693, 1996.

57. DeRyck M, Verhoye M, Van der Linden AM. Diffusion-weighted MRI of infarct growth in a rat photochemical stroke model: effect of lubeluzole. Neuropharmacology 39:691-702, 2000.

58. Scheller DKA, De Ryck M, Kolb J, Szathmary S, van Reempts J, Clincke $\mathrm{G}$ et al. Lubeluzole blocks increases in extracellular glutamate and taurine in the peri-infarct zone in rats. Eur J Pharmacol 338:243-251, 1997.

59. Lesage AS, Peeters L, Leysen JE. Lubeluzole, a novel long-term neuroprotectant, inhibits the glutamate-activated nitric oxide synthase pathway. J Pharmacol Exp Ther 279:759-766, 1996.

60. Diener H, Hacke W, Hennerici M, Radberg J, Hautson L, De Keyser J, for the Lubeluzole International Study Group. Lubeluzole in acute ischemic stroke: a double-blind placebo controlled phase II trial. Stroke 27:76-81, 1996.

61. DeRyck M, Keersmackers R, Duytschaever H, Claes C, Clicke G, Janssen M. Lubeluzole protects sensorimotorfunction and reduces infarct size in a photochemical stroke model. J Pharmacol Exp Ther 35:748-758, 1996.

62. Diener HC. Multinational randomized controlled trial of lubeluzole in acute ischaemic stroke: European and Australian Lubeluzole Ischaemic Stroke Study Group. Cerebrovasc Dis 8:172181, 1998.

63. Grotta J, for the US and Canadian Lubeluzole Ischemic Stroke Study Group. Lubeluzole treatment of acute ischemic stroke. Stroke 28:2338-2346, 1997.

64. Grotta J. Combination Therapy Stroke Trial: Recombinant tissuetype plasminogen activator with/without lubeluzole. Cerebrovasc Dis 12:258-263, 2001.

65. Gandolfo C, Sandercock P, Conti M. Lubeluzole for acute ischaemic stroke. Cochrane Database Syst Rev CD001924, 2002.

66. Davies MF, Deisz RA, Prince DA, Peroutka SJ. Two distinct effects of 5-hydroxytryptamine on single cortical neurons. Brain Res 423:347-352, 1987.

67. Schaper C, Zhu Y, Kouklei M, Culmsee C, Krieglstein J. Stimulation of 5-HT1A receptors reduces apoptosis after transient forebrain ischemia in the rat. Brain Res 883:41-50, 2000.

68. Ramirez-Lessepas M, Patrick BK, Snyder BD, Lakatua DJ. Failure of central nervous system serotonin blockage to influence outcome in acute cerebral infarction: a double-blind randomized trial. Stroke 17:953-956, 1986.

69. Semkova I, Wolz P, Krieglstein J. Neuroprotective effect of 5-HT1A receptor agonist, BAY x 3702, demonstrated in vitro and in vivo. Eur J Pharmacol 359:251, 1998.

70. Bayer Randomized Acute Ischemia Neuroprotectant Study (BRAINS). Abstracts from the 4th World Stroke Congress. Stroke 31:2768, 2000.

71. Teal P, Rombout F, Weber H et al. Repinotan (BAY x 3702) in acute ischemic stroke: a randomized exposure controlled trial. Abstract presented in the Ongoing Clinical Trials Session, 26th International Stroke Conference, Fort Lauderdale, FL, February, 2001. 
72. ONO-2506 in Acute Ischemic Stroke. Stroke Center Clinical Trials Directory. http://www.strokecenter.org/trials/TrialDetail. asp?ref $=469 \&$ browse $=$ acute [updated $11 / 14 / 2002$ ]

73. Harini RJ, Supra EL, Roberts JP, Lavyne MH. Effect of naloxone on cerebral perfusion and cardiac performance during experimental cerebral ischemia. J Neurosurg 64:780-786, 1986.

74. Namba S, Nishigaki S, Fujiwara N, Wani T, Namba Y, Masaoka T. Opiate-antagonist reversal of neurological deficits: experimental and clinical studies. Jpn J Psychiatry Neurol 40:61-79, 1986.

75. Baskin DS, Juroda H, Hosobuchi Y, Lee NM. Treatment of Stroke with optiate antagonists—effects of exogenous antagonist and synorphin 1-13. Neuropeptides 5:307-310, 1987.

76. Fallis RF, Fisher M, Lobo RA. A double-blind trial of naloxone in the treatment of acute stroke. Stroke 15:627-629, 1984.

77. Jabaily J, Davis JN. Naloxone administration to patients with acute stroke. Stroke 15:36-39, 1984

78. Adams HP Jr, Olinger CP, Barsan WG, Butler MJ, Graff-Radford NR, Brott TG et al. A dose-escalation study of large doses of naloxone for treatment of patients with acute cerebral ischemia. Stroke 17:404-409, 1986.

79. Olinger CP, Adams HP Jr, Brott TG, Biller J, Barsan WG, Toffol GJ et al. High-dose intravenous naloxone for the treatment of acute ischemic stroke. Stroke 21:721-725, 1990.

80. Federico F, Lucivero V, Lamberti P, Fiore A, Conte C. A double blind randomized pilot trial of naloxone in the treatment of acute ischemic stroke. Ital J Neurol Sci 12:557-563, 1991.

81. Clark W, Coull B, Karukin M, Hendin B, Kelly BR, Rosing H et al. Randomized trial of Cervene, a $\kappa$ receptor-selective opioid antagonist, in acute ischemic stroke. $J$ Stroke Cerebrovasc Dis 6:35-40, 1996.

82. Clark W, Ertag W, Orecchio E, Raps E. Cervene in acute ischemic stroke: results of a double-blind, placebo-controlled, dosecomparison study. J Stroke Cerebrovasc Dis 8:224-230, 1999.

83. Clark WM, Raps EC, Tong DC, Kelly RE, for the Cervene Stroke Study Investigators. Cervene (nalmefene) in acute ischemic stroke: final results of a phase III efficacy study. Stroke 31:12341239, 2000 .

84. Green AR, Hainsworth AH, Jackson DM. GABA potentiation: a logical pharmacological approach for the treatment of acute ischaemic stroke. Neuropharmacology 39:1483-1494, 2000.

85. Moody IF, Skolnick P. Clomethiazole: neurochemical actions at the gamma-aminobutyric acid complex. Br J Pharmacol 164: $153-158,1989$.

86. Cross AF, Jones JA, Baldwin HA, Green AR. Neuroprotective activity of clomethiazole following transient forebrain ischemia in the gerbil. Br J Pharmacol 104:406-411, 1991.

87. Marshall JWB, Cross AF, Murray TK, Ridley RM. Functional benefit from clomethiazole treatment after focal cerebral ischaemia in a non-human primate species [abstract]. Stroke 29:330, 1998.

88. Wester P, Strand T, Wahlgren NG, Ashwood T, Osswald G. An open study of clomethiazole in patients with acute cerebral infarction. Cerebrovasc Dis 8:188-190, 1998.

89. Sydserff SG, Cross AJ, Murray TK, Jones JA, Green AR et al. Clomethiazole is neuroprotective in models of global and focal cerebral ischemia when infused at doses producing clinically relevant plasma concentrations. Brain Res 862:59-62, 2000.

90. Wahlgren NG, Ranasinha KW, Rosolacci T, Franke CL, van Erven PM, Ashwood T et al, for the CLASS Study Group. Clonethiazole Acute Stroke Study (CLASS): results of a randomized, controlled trial of clomethiazole versus placebo in 1360 acute stroke patients. Stroke 30:21-28, 1999.

91. Wahlgren NG, Diez-Tejedor E, Teitelbaum J, Arboix A, Leys D, Ashwood $\mathrm{T}$ et al, for the CLASS Study Group. Results in 95 hemorrhagic stroke patients included in CLASS, a controlled trial of clomethiazole versus placebo in acute stroke patients. Stroke 31:82-85, 2000.

92. Lyden P, Shuaib A, Ng K, Levin K, Atkinson RP, Rajput A et al. The CLASS-I/H/T Investigators: Clomethiazole Acute Stroke Study in ischemic stroke (CLASS-I): final results. Stroke 33:122128, 2002.

93. Lodder J, Raak van EPM, Kessels F. Early GABA-ergic activation study in stroke. Abstract presented at the Ongoing Clinical
Trials Session, 26th International Stroke Conference, Fort Lauderdale, FL, February, 2001.

94. Hall ED, Pazara KE, Braughler JM. 21-aminosteroid lipid peroxidation inhibitor U74006F protects against cerebral ischemia in gerbils. Stroke 19:997-1002, 1988.

95. Zuccarello M, Marsch JT, Schmitt G, Woodward J, Anderson DK. Effect of the 21-aminosteroid U-74006 on cerebra vasospasm following subarachnoid hemorrhage. $J$ Neurosurg 71:98104, 1989.

96. Hall ED, Andrus PK, Smith SL, Oostveen JA, Scherch HM, Lutzke BS et al. Neuroprotective efficacy of microvascularlylocalized versus brain-penetrating antioxidants. Acta Neurochir Suppl (Wien) 66:107-113, 1996.

97. The STIPAS Investigators. Safety study of tirilazad mesylate in patients with acute ischemia stroke (STIPAS). Stroke 25:418 423, 1994.

98. The RANTTAS Investigators. A randomized trial of tirilazad mesylate in patients with acute stroke (RANTTAS). Stroke 27: $1453-1458,1996$

99. Haley EC, on behalf of the RANTTAS II Investigators. Highdose tirilazad for acute stroke (RANTTAS II). Stroke 29:12561257, 1998

100. Tirilazad International Steering Committee. Tirilazad mesylate in acute ischemic stroke: a systematic review. Stroke 32:2257-2265, 2000.

101. Van der Worp HB, Kappelle LJ, Algra A, Bar PR, Orgogozo JM, Ringelstein EB et al, on behalf of the TESS and TESS II Investigators. The effect of tirilazad mesylate on infarct volume of patients with acute ischemic stroke. Neurology 58:133-135, 2002.

102. Beck T, Bielenberg GW. Failure of the lipid peroxidation inhibitor U74006F to improve neurological outcome after transient forebrain ischemia in the rat. Brain Res 532:336-338, 1990.

103. Ichikawa S, Omura K, Katayama T, Okamura N, Ontsuka T, Ishibashi $\mathrm{S}$ et al. Inhibition of superoxide anion production in guinea pig polymorphonuclear leudocytes by a seleno-organic compound, ebselen. J Pharmacobio-Dyn 10:595-597, 1987.

104. Hattori R, Inoue R, Sase K, Eizawa H, Kosuga K, Aoyama T et al. Preferential inhibition of inducible nitric oxide synthase by ebselen. Eur J Pharmacol 267:R1-R2, 1994.

105. Maiorino M, Roveri A, Coassin M, Ursini F. Kinetic mechanism and substrate specificity of glutathione peroxidase activity of ebselen (PZ51). Biochem Pharmacol 37:2267-2271, 1988.

106. Yamaguchi T, Sano K, Takakura K, Saito I, Shinohara Y, Asano $\mathrm{T}$ et al, for the Ebselen Study Group. Ebselen in acute ischemic stroke: A placebo-controlled, double-blind clinical trial. Stroke 29:12-17, 1998.

107. Zhao Z, Cheng M, Maples KR, Ma JY, Buchan AM et al. NXY059 , a novel free radical trapping compound, reduces cortical infarction after permanent focal cerebral ischemia in the rat. Brain Res 909:46-50, 2001.

108. Sydserff SG, Borelli AR, Green AR, Cross AJ. Effect of NSY059 on infarct volume after transient or permanent middle cerebral artery occlusion in the rat: Studies on dose, plasma concentration and therapeutic time window. Br J Pharmacol 135:103$112,2002$.

109. Marshall JWB, Duffin KJ, Green AR, Ridley RM. NXY-059, a free radical-trapping agent, substantially lessens the functional disability resulting from cerebral ischemia in a primate species. Stroke 32:190-198, 2001.

110. Cross AJ. The effect of increasing doses of NXY-059 on infarct size following permanent middle cerebral artery occlusion in the rat. AstraZeneca Report. 2000.

111. Lees KR, Sharma AK, Barer D, Ford GA, Kostulas V, Cheng YF et al, for the SA-NXY-0003 Investigators. Tolerability and pharmacokinetics of the nitrone NXY-059 in patients with acute stroke. Stroke 32:675-680, 2001.

112. Okada Y, Copeland BR, More E, Tung MM, Thomas WS, del Zoppo GJ et al. P-selectin and intercellular adhesion molecule-1 expression after focal brain ischemia and reperfusion. Stroke 25 : 202-211, 1994.

113. Zhang RL, Chopp M, Zaloga C, Zhang ZG, Jiang N, Gautam SC et al. The temporal profiles of ICAM-1 protein and mRNA ex- 
pression after transient MCA occlusion in the rat. Brain Res 682:182-188, 1995.

114. Soriano SG, Coxon A, Wang YF, Frosch MP, Lipton SA, Hickey PR et al. Mice deficient in Mac-1(CD11b/CD18) are less susceptible to cerebral ischemia/reperfusion injury. Stroke 30:134-139, 1999.

115. Kitagawa K, Matsumoto M, Mabuchi T, Yagita Y, Ohtsuki T, Hori $\mathrm{M}$ et al. Deficiency of intercellular adhesion molecule-1 attenuates microcirculatory disturbance and infarction size in focal cerebral ischemia. J Cereb Blood Flow Metab 18:1336-1345, 1998.

116. Clark WM, Madden KP, Rothlein R, Zivin JA. Reduction of central nervous system ischemic injury in rabbits using leukocyte adhesion antibody treatment. Stroke 22:877-883, 1991.

117. Zhang RL, Chopp M, Jiang N, Tang WX, Prostak J, Manning AM et al. Anti-intercellular adhesion molecule-1 antibody reduces ischemic cell damage after transient but not permanent middle cerebral artery occlusion in the Wistar rat. Stroke 26:1438-1442, 1995.

118. Zhang RL, Zhang ZG, Chopp M, Zivin JA. Thrombolysis with tissue plasminogen activator alters adhesion molecule expression in the ischemic rat brain. Stroke 30:624-629, 1999.

119. Fassbender K, Mossner R, Motsch L, Kischka V, Garu A, Hennerici M. Circulating selectin- and immunoglobulin-type adhesion molecules in acute ischemic stroke. Stroke 26:1361-1364, 1995.

120. Bitsch A, Klene W, Murtada L, Prange H, Rieckmann P. A longitudinal prospective study of soluble adhesion molecules in acute stroke. Stroke 29:2129-2135, 1998.

121. Frijns CJ, Kappelle LJ, van Gijn J, Nieuwenhuis HK, Sixma JJ, Fijnheer R. Soluble adhesion molecules reflect endothelial cell activation in ischemic stroke and in carotid atherosclerosis. Stroke 28:2214-2218, 1997.

122. Lindsberg PJ, Carpen O, Paetau A, Karjalainen-Lindsberg ML, Kaste M. Endothelial ICAM-1 expression associated with inflammatory cell response in human ischemic stroke. Circulation 94: 939-945, 1996.

123. Schneider D, Berrouschot J, Brandt T, Hacke W, Ferbert A, Norris SH. Safety, pharmacokinetics and biological activity of enlimomab (anti-ICAM-1 antibody): an open-label, dose escalation study in patients hospitalized for acute stroke. Eur Neurol 40:78-83, 1998.

124. Enlimomab Acute Stroke Trial Investigators. Use of anti-ICAM-1 therapy in ischemic stroke: results of the Enlimomab Acute Stroke Trial. Neurology 57:1428-1434, 2001

125. Furuya K, Takeda H, Azhar S, McCarron RM, Chen Y, Ruetzler $\mathrm{CA}$ et al. Examination of several potential mechanisms for the negative outcome in a clinical stroke trial of enlimomab, a murine anti-human intercellular adhesion molecule-1 antibody: a bedside-to-bench study. Stroke 32:2665-2674, 2001.

126. Manabat C, Han BH, Wendland M, Derugin N, Fox CK, Choi J et al. Reperfusion differentially induces caspases-3 activation in ischemic core and penumbra after stroke in immature brain. Stroke 34:207-213, 2003.

127. Robertson GS, Crocker SJ, Nicholson DW, Schulz JB. Neuroprotection by the inhibition of apoptosis. Brain Pathol 10:283292, 2000.

128. Satoh S, Ikegaki I, Suzuki Y, Asano T, Shibuya M, Hidaka H. Neuroprotective properties of a protein kinase inhibitor against ischaemia-induced neuronal damage in rats and gerbils. $\mathrm{Br} J$ Pharmacol 118:1592-1596, 1996.

129. Wang KKW, Nath R, Rosner A, Raser J, Buroker-Kilgore M, Hajimohammadreza I et al. An alpha-mercaptoacrylic acid derivative is a selective nonpeptide cell-permeable calpain inhibitor and is neuroprotective. Proc Natl Acad Sci USA 93:6687-6692, 1996.

130. Barone FC, Irving EA, Ray AM, Lee JC, Kassis S, Kumar S et al. SB 239063, a second-generation p38 mitogen-activated protein kinase inhibitor, reduces brain injury and neurological deficits in cerebral focal ischemia. J Pharmacol Exp Ther 296:312-321, 2001.

131. Markgraf CG, Velayo NL, Johnson MP, McCarty DR, Medhi S, Koehl JR et al. Six-hour window of opportunity for calpain inhibition in focal cerebral ischemia in rats. Stroke 29:152-158, 1998.

132. Yrjanheikki J, Keinanen R, Pellikka M, Hokfelt T, Koistinaho J et al. Tetracyclines inhibit microglial activation and are neuro- protective in global brain ischemia. Proc Natl Acad Sci USA 95:15769-15774, 1998.

133. Yrjanheikki J, Tikka T, Keinanen R, Goldsteins G, Chan PH, Koistinaho J. A tetracycline derivative, minocycline, reduces inflammation and protects against focal cerebral ischemia with a wide therapeutic window. Proc Natl Acad Sci USA 96:1349613500, 1999.

134. Wang C, Yang T, Noor R, Shuaib A. Delayed minocycline but not delayed mild hypothermia protects against embolic stroke. BMC Neurol 2:2, 2002.

135. Asai A, Qiu J, Narita Y, Chi S, Saito N, Shinoura N et al. High level calcineurin activity predisposes neuronal cells to apoptosis. J Biol Chem 274:34450-34458, 1999.

136. Herr I, Martin-Villalba A, Kurz E, Roncaioli P, Schenkel J, Cifone MG et al. FK506 prevents stroke-induced generation of ceramide and apoptosis signaling. Brain Res 826:210-219, 1999.

137. Bochelen D, Rudin M, Sauter A. Calcineurin inhibitors FK506 and SDZ ASM 981 alleviate the outcome of focal cerebral ischemic/reperfusion injury. J Pharmacol Exp Ther 288:653-659, 1999.

138. Ebisu T, Katsuta K, Fujikawa A, Aoki I, Vaneda M, Naruse S et al. Early and delayed neuroprotective effects of FK506 on experimental focal ischemia quantitatively assessed by diffusionweighted MRI. Magn Reson Imaging 19:153-160, 2001.

139. McCarter JF, McGregor AL, Jones PA, Sharkey J. FK506 protects brain tissue in animal models of stroke. Transplant Proc 33:2390-2392, 2001

140. Arii T, Kamiya T, Arii K, Ueda M, Nito C, Katsura KI et al. Neuroprotective effect of immunosuppressant FK506 in transient focal ischemia in rat: Therapeutic time window for FK506 in transient focal ischemia. Neurol Res 23:755-760, 2001.

141. Takamatsu H, Tsukada H, Noda A, Kakiuchi T, Nishiyama S, Nishimura S et al. FK506 attenuates early ischemic neuronal death in a monkey model of stroke. J Nucl Med 42:1833-1840, 2001.

142. Limbourg FP, Huang Z, Plumier JC, Simoncini T, Fujioka M, Tuckermann $\mathrm{J}$ et al. Rapid nontranscriptional activation of endothelial nitric oxide synthase mediates increased cerebral blood flow and stroke protection by corticosteroids. J Clin Invest 110 : 1729-1738, 2002.

143. Mulley G, Wilcox RG, Mitchell JR. Dexamethasone in acute stroke. BMJ 2:994-996, 1978

144. Norris JW, Hachinski VC. High dose steroid treatment in cerebral infarction. BMJ 292:21-23, 1986.

145. Qizilbash N, Lewington SL, Lopez-Arrieta JM. Corticosteroids for acute ischaemic stroke. Cochrane Database Syst Rev CD000064-2, 2000

146. Vayssiere BM, Dupont S, Choquart A, Petit F, Garcia T, Marchandeau $\mathrm{C}$ et al. Synthetic glucocorticoids that dissociate transactivation and AP-1 transrepression exhibit anti-inflammatory activity in vivo. Mol Endocrinol 11:1245-1255, 1997.

147. Belayev L, Liu Y, Zhao W, Busto R, Ginsburg MD. Human albumin therapy of acute ischemic stroke: marked neuroprotective efficacy at moderate doses and with a broad therapeutic window. Stroke 32:553-560, 2001.

148. Zoellner H, Hofler M, Beckmann R, Hufnagl P, Vanyek E, Bielek $\mathrm{E}$ et al. Serum albumin is a specific inhibitor of apoptosis in human endothelial cells. J Cell Sci 109:2571-2580, 1996.

149. Rodriguez de Turco IB, Belayev L, Liu Y, Busto R, Parkins N, Bazan NG et al. Systemic fatty acid responses to transient focal cerebral ischemia: influence of neuroprotectant therapy with human albumin. J Neurochem 83:515-524, 2002.

150. Lenzi GL, Grigoletto F, Gent M, Roberts RS, Walker MD, Easton JD et al and the Early Stroke Trial Group. Early treatment of stroke with monosialoganglioside GM-1: Efficacy and safety results of the early stroke trial. Stroke 25:1552-1558, 1994.

151. Schwab M, Antonow-Schorke I, Zwiener U, Bauer R. Brainderived peptides reduce the size of cerebral infarction and loss of MAP2 immunoreactivity after focal ischemia in rats. $J$ Neural Transm Suppl 53:299-311, 1998.

152. Ladurner F. Neuroprotection in acute ischaemic stroke [abstract]. Stroke 32:323, 2001.

153. Rao AM, Hatcher JF, Dempsey RJ. CDP-choline: neuroprotec- 
tion in transient forebrain ischemia of gerbils. $J$ Neurosci Res 58:697-705, 1999.

154. Adibhatla RM, Hatcher JF, Dempsey RJ. Citicoline: neuroprotective mechanisms in cerebral ischemia. $J$ Neurochem $80: 12-23$, 2002.

155. Krupinski J, Ferrer I, Barrachina M, Secades JJ, Mercadal J, Lozano $\mathrm{R}$ et al. CDP-choline reduces procaspase and cleaved caspae-3 expression, nuclear DNA fragmentation, and specific PARP-cleaved products of caspase activation following middle cerebral artery occlusion in the rat. Neuropharmacology 42:846854,2002

156. Clark W, Warach S, for the Citicholine Study Group. Randomized dose response trial of citicholine in acute ischemic stroke patients. Neurology 49:671-678, 1997.

157. Clark WM, Williams BJ, Selzer KA et al, for the Citicoline Stroke Study Group. A randomized efficacy trial of citicoline in patients with acute ischemic stroke. Stroke 30:2592-2597, 1999.

158. Clark WM, Wechsler LR, Sabounjian LA, Schwiderski UE, for the Citicoline Stroke Study Group. A phase III randomized efficacy trial of $2000 \mathrm{mg}$ citicoline in acute ischemic stroke patients. Neurology 57:1595-1602, 2001.

159. Warach S, Pettigrew LC, Dashe JF, Pullicino P, Lefkowitz DM, Sabounjian L et al. Effect of citicoline on ischemic lesions as measured by diffusion-weighted magnetic resonance imaging. Citicoline 010 Investigators. Ann Neurol 48:713-722, 2000.

160. Corso A, Arena M, Ventimiglia A, Bizzarro G, Campo G, Rodolico F. CDP-choline for cerebrovascular disorders: Clinical evaluation and evaluation of electrophysiological symptomology. Clin Ter 102:379-386, 1982.

161. Tazaki Y, Sakai F, Otomo E, Kutsuzawa T, Kameyama M, Omae $\mathrm{T}$ et al. Treatment of acute cerebral infarction with a choline precursor in a multicenter double-blind placebo-controlled study. Stroke 19:211-216, 1988.

162. Saver J, Wilterdink J. Choline precursors in acute and subacute stroke: a meta-analysis. Stroke 33:353, 2002.

163. Davalos A, Castillo J, Alvarez-Sabin J, Secades JJ, Mercadal J, Lopez $\mathrm{S}$ et al. Oral citicoline in acute ischemic stroke: an individual patient data pooling analysis of clinical trials. Stroke 33: 2850-2857, 2002.

164. Andersen M, Overgaard K, Meden P, Boysen G. Effects of citicoline combined with thrombolytic therapy in a rat embolic stroke model. Stroke 30:1464-1471, 1999.

165. Siren AL, Ehrenreich H. Erythropoietin-a novel concept for neuroprotection. Eur Arch Psychiatry Clin Neurosci 251:179-184, 2001.

166. Sakanaka M, Wen TC, Matsuda S, Morishita E, Nagao M et al. In vitro evidence that erythropoietin protects neurons from ischemic damage. Proc Natl Acad Sci USA 95:4635-4640, 1998.

167. Morishita E, Masuda S, Nagao M, Yasuda Y, Sasaki R. Erythropoietin receptor is expressed in rat hippocampal and cerebral cortical neurons, and erythropoietin prevents in vitro glutamateinduced neuronal death. Neuroscience 76:105-116, 1997.

168. Brines ML, Ghezzi P, Keenan S, Angello D, de Lanerolle M, Cerami $\mathrm{C}$ et al. Erythropoietin crosses the blood-brain barrier to protect against experimental brain injury. Proc Natl Acad Sci USA 97:10526-10531, 2000.

169. Siren AL, Fratelli M, Brines M et al. Erythropoietin prevents neuronal apoptosis after cerebral ischemia and metabolic stress. Proc Natl Acad Sci USA 98:4044-4049, 2000.

170. Ay I, Sugimori H, Finklestein SP. Intravenous basic fibroblast growth factor (bFGF) decreases DNA fragmentation and prevents downregulation of $\mathrm{Bcl}-2$ expression in the ischemic brain following middle cerebral artery occlusion in rats. Mol Brain Res 87: 71-80, 2001.

171. Kawamata T, Kietrich WD, Schallert T, Gotts JE, Cocke RR, Benowitz LI et al. Intracisternal basic fibroblast growth factor enhances functional recovery and up-regulates the expression of a molecular marker of neuronal sprouting following focal cerebral infarction. Proc Natl Acad Sci USA 94:8179-8184, 1997.

172. Li Q, Stephenson D. Postischemic administration of basic fibroblast growth factor improves sensorimotor function and reduces infarct size following permanent focal cerebral ischemia in the rat. Exp Neurol 177:531-537, 2002.
173. Schabitz WR, Li F, Irie K, Sandage BW Jr, Locke KW, Fisher M et al. Synergistic effects of a combination of low-dose basic fibroblast growth factor and citicoline after temporary experimental focal ischemia. Stroke 30:427-431, 1999.

174. Ma J, Aui J, Hirt L, Dalkara T, Moskowitz MA. Synergistic protective effect of caspases inhibitors and bFGF against brain injury induced by transient focal ischaemia. Br J Pharmacol 133:345-350, 2001.

175. Bogousslavsky J, Victor SJ, Salinas EO, Pallay A, Ponnan GA, Fieschi $\mathrm{C}$ et al, for the European-Australian Fiblast in Acute Stroke Group. Fiblast (trafermin) in acute stroke: results of the Eur-Australian phase II/III safety and efficacy trial. Cerebrovasc Dis 14:239-251, 2002.

176. Song BW, Vinters HV, Wu D, Pardridge WM. Enhanced neuroprotective effects of basic fibroblast growth factor in regional brain ischemia after conjugation to a blood-brain barrier delivery vector. J Pharmacol Exp Ther 301:605-610, 2002.

177. Krupinski J, Issa R, Bujny T, Slevin M, Kumar P, Kamar S et al. A putative role for platelet-derived growth factor in angiogenesis and neuroprotection after ischemic stroke in humans. Stroke 28 : 564-573, 1997.

178. Semkova I, Krieglstein J. Neuroprotection mediated via neurotrophic factors and induction of neurotrophic factors. Brain Res Rev 30:176-188, 1999.

179. Wang Y, Chang CF, Morales M, Chang YH, Hoffer J. Protective effects of glial cell line-derived neurotrophic factor in ischemic brain injury. Ann N Y Acad Sci 962:423-437, 2002.

180. Kilic E, Dietz GPH, Hermann DM, Bahr M. Intravenous TATBcl-XL is protective after middle cerebral artery occlusion in mice. Ann Neurol 52:617-622, 2002.

181. Busto R, Dietrich WD, Globus MY, Valdes I, Scheinberg P, Ginsberg MD. Small differences in intraischemic brain temperature critically determine the extent of ischemic neuronal injury. J Cereb Blood Flow Metab 7:729-738, 1987.

182. Buchan A, Pulsinell WA. Hypothermia but not N-methyl-D-aspartate antagonist MK-801 attenuates neuronal damage in gerbils subjected to transient global ischemia. $J$ Neurosci 10:311-316, 1990.

183. Minamisawa H, Nordstrom CH, Smith ML, Siesjo BK. The influence of mild body and brain hypothermia on ischemic brain damage. J Cereb Blood Flow Metab 10:365-374, 1990.

184. Coimbra C, Wielock T. Hypothermia ameliorates neuronal survival when induced 2 hours after ischemia in the rat. Acta Physiol Scand 146:543-544, 1992.

185. Meden P, Overguard K, Pedersen H, Boysen G. The influence of body temperature on infarct volume and thrombolytic therapy in a rat embolic stroke model. Brain Res 647:131-138, 1994.

186. Corbett D, Nurse S, Colbourne F. Hypothermic neuroprotection: a global ischemia study using 18- to 20-month-old gerbils. Stroke 28:2238-2242, 1997.

187. Barone FC, Feuerstein GZ, White RF. Brain cooling during transient focal ischemia provides complete neuroprotection. Neurosci Biobehav Rev 21:31-44, 1997.

188. Maier CM, Ahern KB, Cheng ML, Lee JE, Yenari MA, Steinberg GK et al. Optimal depth and duration of mild hypothermia in a focal model of transient cerebral ischemia: Effects of neurologic outcome, infarct size, apoptosis, and inflammation. Stroke 29: 2171-2180, 1998.

189. Corbett D, Hamilton M, Colbourne F. Persistent neuroprotection with prolonged postischemic hypothermia in adult rats subjected to transient middle cerebral artery occlusion. Exp Neurol 163: 200-206, 2000.

190. Kawai N, Okauchi M, Morisaki K, Nagao S. Effects of delayed intraischemic and postischemic hypothermia on a focal model of transient cerebral ischemia in rats. Stroke 31:1982-1989, 2000.

191. Nakashima K, Todd MM. Effects of hypothermia on the rate of excitatory amino acid release after ischemic depolarization. Stroke 27:913-918, 1996.

192. Koizumi H, Fujisawa H, Ito H, Maekawa T, Pi X, Bullock R. Effects of mild hypothermia on cerebral blood flow-independent changes in cortical extracellular levels of amino acids following contusion trauma in the rat. Brain Res 747:304-312, 1997.

193. Sick TJ, Xu G, Perez-Pinzon AM. Mild hypothermia improves 
recovery of cortical extracellular potassium ion activity and excitability after middle cerebral artery occlusion in the rat. Stroke 30:2416-2421, 1999.

194. Prakasa Babu PP, Yoshida Y, Su M, Segura M, Kawamura S, Yasui $\mathrm{N}$ et al. Immunohistochemical expression of $\mathrm{Bcl}-2$, Bax and cytochrome $\mathrm{c}$ following focal cerebral ischemia and effect of hypothermia in rat. Neurosci Lett 291:196-200, 2000.

195. Ishikawa M, Sekizuka E, Sato S, Yamaguchi N, Inamasu J, Bertalanffy $\mathrm{H}$ et al. Effects of moderate hypothermia on leukocyte-endothelium interaction in the rat pial microvasculature after transient middle cerebral artery occlusion. Stroke 30:1679-1686, 1999.

196. Inamasu J, Suga S, Sato S, Horiguchi T, Akaji K, Mayanogi K et al. Post-ischemic hypothermia delayed neutrophil accumulation and microglial activation following transient focal cerebral ischemia in rats. J Neuroimmunol 109:66-74, 2000.

197. Zeiner A, Holzer M, Sterz F, Behringer W, Schorkuber W, Mullner $\mathrm{M}$ et al. for the Hypothermia After Cardiac Arrest (HACA) Study Group. Mild resuscitative hypothermia to improve neurological outcome after cardiac arrest. Stroke 31:86-94, 2000.

198. Felberg RA, Krieger DW, Chuang R, Persse PE, Burgin WS, Hickenbottom SL et al. Hypothermia after cardiac arrest: feasibility and safety of an external cooling protocol. Circulation 104:1799-1804, 2001.

199. Bernard SA, Gray TW, Buist MD, Jones BM, Silvester W, Gutteridge $\mathrm{G}$ et al. Treatment of comatose survivors of out-of-hospital cardiac arrest with induced hypothermia. $N$ Engl $\mathrm{J}$ Med 346:557-563, 2002.

200. The Hypothermia After Cardiac Arrest Study Group. Mild therapeutic hypothermia to improve the neurologic outcome after cardiac arrest. $N$ Engl J Med 346:549-556, 2002.

201. Colbourne F, Li H, Buchan AM. Indefatigable CA1 sector neuroprotection with mild hypothermia induced 6 hours after severe forebrain ischemia in rats. J Cereb Blood Flow Metab 19:742749, 1999.

202. Azzimondi G, Bassein L, Nonino F, Fiorani L, Vignatelli L, Re G et al. Fever in acute stroke worsens prognosis. Stroke 26:20402043, 1995.

203. Jorgensen HS, Reith J, Pedersen PM, Nakayama H, Olsen TS. Body temperature and outcome in stroke patients [letter]. Lancet 348:193, 1996.

204. Reith J, Jorgensen HS, Pedersen PM, Nakayama H, Raaschou HO, Jeppesen LL et al. Body temperature in acute stroke: relation to stroke severity, infarct size, mortality, and outcome. Lancet 347:422-425, 1996.

205. Wang Y, Lim LL, Levi C, Heller RF, Fischer J. Influence of admission body temperature on stroke mortality. Stroke 31:404409, 2000.

206. Schwab S, Schwarz S, Spranger M, Keller E, Bertram M, Hacke W. Moderate hypothermia in the treatment of patients with severe middle cerebral artery infarction. Stroke 29:2461-2466, 1998.

207. Kammersgaard LP, Rasmussen BH, Jorgensen HS, Reith J, Weber U, Olsen TS. Feasibility and safety of inducing modest hypothermia in awake patients with acute stroke through surface cooling: a case-control study. Stroke 31:2251-2256, 2000.

208. Schwab S, Georgiadis D, Berrouschot J, Schellinger PB, Graffagnino C, Mayer SA. Feasibility and safety of moderate hypothermia after massive hemispheric infarction. Stroke 32:20332035, 2001.

209. Steiner T, Friede T, Aschoff A, Schellinger PD, Schwab S, Hacke W. Effect and feasibility of controlled rewarming after moderate hypothermia in stroke patients with malignant infarction of the middle cerebral artery. Stroke 32:2833-2835, 2001.

210. Kreiger DW, DeGeorgia MA, Abou-Chebl A, Andrefsky JC, Sila CA, Katzan IL et al. Cooling for Acute Ischemic Brain Damage (COOL AID): an open pilot study of induced hypothermia in acute ischemic stroke. Stroke 32:1847-1854, 2001.

211. Georgiadis D, Schwarz S, Kollmar R, Schwab S. Endovascular cooling for moderate hypothermia in patients with acute stroke: first results of a novel approach. Stroke 32:2550-2553, 2001.

212. Strong R, Grotta JC, Aronowski J. Combination of low dose ethanol and caffeine protects brain from damage produced by focal ischemia in rats. Neuropharmacology 39:515-522, 2000.

213. Aronowski J, Strong R, Shirzadi A, Grotta JC. Ethanol plus caffeine (caffeinol) for treatment of ischemic stroke: preclinical experience. Stroke 34:1246-1251, 2003.

214. Piriyawat P, Labiche LA, Burgin WS, Aronowski JA, Grotta JC. Pilot dose-escalation study of caffeine plus ethanol (Caffeinol) in acute ischemic stroke. Stroke 34:1242-1245, 2003.

215. Bowes M, Burhop K, Zivin J. Diaspirin cross-linked hemoglobin improves neurological outcome following reversible but not irreversible CNS ischemia in rabbits. Stroke 25:2253-2257, 1994.

216. Cole D, Schell R, Przybelski R, Drummond JC, Bradley K. Focal cerebral ischemia in rats: effect of hemodilution with cross-linked hemoglobin on CBF. J Cereb Blood Flow Metab 12:971-976, 1992.

217. Cole D, Schell R, Drummond J, Reynolds L. Focal cerebral ischemia in rats: effect of hypervolemic hemodilution with diaspirin crossed-linked hemoglobin versus albumin on brain injury and edema. Anesthesiology 78:335-342, 1993.

218. Grotta J, Aronowski J. DCLHb for focal ischemia and reperfusion. Cerebrovasc Dis 6:189, 1996.

219. Saxena R, Wijnhoud AD, Carton H, Hacke W, Kaste M, Przybelski RJ et al. Controlled safety study of a hemoglobin-based oxygen carrier, DCLHb, in acute ischemic stroke. Stroke 30:993996, 1999.

220. Singhal AB, Dijkhuizen RM, Rosen B, Lo EH. Normobaric hyperoxia reduces MRI diffusion abnormalities and infarct size in experimental stroke. Neurology 58:945-952, 2002.

221. Atochin DN, Fisher D, Demchenko IT, Thom SR. Neutrophil sequestration and the effect of hyperbaric oxygen in a rat model of temporary middle cerebral artery occlusion. Undersea Hyperb Med 27:185-190, 2000.

222. Badr AE, Yin W, Mychaskiw G, Zhang JH. Effect of hyperbaric oxygen on striatal metabolites: A microdialysis study in awake freely moving rats after MCA occlusion. Brain Res 916:85-90, 2001.

223. Burt JT, Kapp JP, Smith RR. Hyperbaric oxygen and cerebral infarction in the gerbil. Surg Neurol 28:265-268, 1987.

224. Weinstein PR, Anderson GG, Telles DA. Results of hyperbaric oxygen therapy during temporary middle cerebral artery occlusion in unanesthetized cats. Neurosurg 20:518-524, 1987.

225. Veltkamp R, Warner DS, Domoki F, Brinkhous AD, Toole JF, Busija DW. Hyperbaric oxygen decreases infarct size and behavioral deficit after transient focal cerebral ischemia in rats. Brain Res 853:68-73, 2000.

226. Chang CF, Niu KC, Hoffer BJ, Wang Y, Borlongan CV. Hyperbaric oxygen therapy for treatment of postischemic stroke in adult rats. Exp Neurol 166:298-306, 2000.

227. Sunami K, Takeda Y, Hashimoto M, Hirakawa M. Hyperbaric oxygen reduces infarct volume in rats by increasing oxygen supply to the ischemic periphery. Crit Care Med 28:2831-2836, 2000.

228. Jacobson I, Lawson DD. The effect of hyperbaric oxygen on experimental cerebral infarction in the dog. J Neurosurg 20:849$859,1963$.

229. Roos JA, Jackson-Friedman, Lyden P. Effects of hyperbaric oxygen on neurologic outcome for cerebral ischemia in rats. Acad Emerg Med 5:18-24, 1998.

230. Hjelde A, Hjelstuen M, Haraldseth O, Martin D, Thom R, Brubakk O. Hyperbaric oxygen and neutrophil accumulation/ tissue damage during permanent focal cerebral ischaemia in rats. Eur J Appl Physiol 86:401-405, 2002.

231. Anderson DC, Bottini AG, Jagiella WM, Westphal B, Ford S, Rockswold GL et al. A pilot study of hyperbaric oxygen in the treatment of human stroke. Stroke 22:1137-1142, 1991.

232. Nighoghossian N, Trouillas P, Adeleine P, Salord F. Hyperbaric oxygen in the treatment of acute ischemic stroke: a double-blind pilot study. Stroke 26:1369-1372, 1995. 